\title{
Localized Sympathectomy Reduces Mechanical Hypersensitivity by Restoring Normal Immune Homeostasis in Rat Models of Inflammatory Pain
}

\author{
Wenrui Xie, ${ }^{1}$ Sisi Chen, ${ }^{1}$ - Judith A. Strong, ${ }^{1}$ Ai-Ling Li, ${ }^{1}$ Ian P. Lewkowich, ${ }^{2}$ and $\odot$ Jun-Ming Zhang ${ }^{1}$ \\ ${ }^{1}$ Pain Research Center, Department of Anesthesiology, University of Cincinnati College of Medicine, Cincinnati, Ohio 45267, and \\ ${ }^{2}$ Division of Immunobiology, Cincinnati Children's Hospital Medical Center, Cincinnati, Ohio 45229
}

Some forms of chronic pain are maintained or enhanced by activity in the sympathetic nervous system (SNS), but attempts to model this have yielded conflicting findings. The SNS has both pro- and anti-inflammatory effects on immunity, confounding the interpretation of experiments using global sympathectomy methods. We performed a "microsympathectomy" by cutting the ipsilateral gray rami where they entered the spinal nerves near the L4 and L5 DRG. This led to profound sustained reductions in pain behaviors induced by local DRG inflammation (a rat model of low back pain) and by a peripheral paw inflammation model. Effects of microsympathectomy were evident within one day, making it unlikely that blocking sympathetic sprouting in the local DRGs or hindpaw was the sole mechanism. Prior microsympathectomy greatly reduced hyperexcitability of sensory neurons induced by local DRG inflammation observed $4 \mathrm{~d}$ later. Microsympathectomy reduced local inflammation and macrophage density in the affected tissues (as indicated by paw swelling and histochemical staining). Cytokine profiling in locally inflamed DRG showed increases in pro-inflammatory Type 1 cytokines and decreases in the Type 2 cytokines present at baseline, changes that were mitigated by microsympathectomy. Microsympathectomy was also effective in reducing established pain behaviors in the local DRG inflammation model. We conclude that the effect of sympathetic fibers in the L4/L5 gray rami in these models is pro-inflammatory. This raises the possibility that therapeutic interventions targeting gray rami might be useful in some chronic inflammatory pain conditions.

Key words: allodynia; cytokine; inflammation; sympathetic

Significance Statement

Sympathetic blockade is used for many pain conditions, but preclinical studies show both pro- and anti-nociceptive effects. The sympathetic nervous system also has both pro- and anti-inflammatory effects on immune tissues and cells. We examined effects of a very localized sympathectomy. By cutting the gray rami to the spinal nerves near the lumbar sensory ganglia, we avoided widespread sympathetic denervation. This procedure profoundly reduced mechanical pain behaviors induced by a back pain model and a model of peripheral inflammatory pain. One possible mechanism was reduction of inflammation in the sympathetically denervated regions. This raises the possibility that therapeutic interventions targeting gray rami might be useful in some inflammatory conditions.

\section{Introduction}

Many chronic pain conditions are thought to be exacerbated or maintained by sympathetic nervous system (SNS) activity (Scad-

\footnotetext{
Received Nov. 16, 2015; revised June 21, 2016; accepted July 9, 2016.

Author contributions: W.X., J.A.S., I.P.L., and J.-M.Z. designed research; W.X., S.C., and A.-L.L. performed research; W.X., S.C., J.A.S., I.P.L., and J.-M.Z. analyzed data; J.A.S. wrote the paper.

This work was supported in part by National Institutes of Health Grants NS045594 and NS055860 to J.-M.Z. We thank Steve Davidson for commenting on the manuscript.

The authors declare no competing financial interests.

Correspondence should be addressed to Dr. Jun-Ming Zhang, Pain Research Center, Department of Anesthesiology, University of Cincinnati, 231 Albert Sabin Way, Cincinnati, 0H 45267-0531. E-mail: Jun-Ming.Zhang@uc.edu.

A.-L. Li's present address: Department of Psychological and Brain Science, Indiana University Bloomington, 702 N Walnut Grove Avenue, Bloomington, IN 47405.
}

ding, 1999; Drummond, 2013; Borchers and Gershwin, 2014; Mantyh, 2014; Schlereth et al., 2014). Local sympathetic blockade or lesion is commonly used to treat pain conditions, including complex regional pain syndrome (CRPS), failed back surgery syndrome, phantom limb pain, postherpetic neuralgia, ischemic pain, and cancer pain (Sekhadia et al., 2011; Harden et al., 2013). However, clinical trials testing its efficacy are scarce and often lack proper blinding, randomization, placebo/sham controls, and/or validated outcome measures (Straube et al., 2010, 2013; Dworkin et al., 2013; Abramov, 2014; Zernikow et al., 2015). 
Because peripheral nerve injury induces sprouting of sympathetic fibers into the dorsal root ganglia (DRGs), many preclinical studies focus on abnormal interactions between the sympathetic and sensory systems (Chung et al., 1993; McLachlan et al., 1993; Ramer and Bisby, 1997; Lee et al., 1998; Pertin et al., 2007). Rodent studies give conflicting results about effects of sympathectomy on pain behaviors (see Discussion). A further complication is that the SNS also influences cells of the immune system. Studies of sympathetic innervation of immune tissues (e.g., thymus, spleen), where sympathetic fibers make synaptic-like close contacts with immune cells, or in nonimmune tissues, often indicate an anti-inflammatory (or Th2-skewing) role (Strausbaugh et al., 2003; Haug and Heyeraas, 2006; Straub et al., 2006; Elenkov, 2008; Perez et al., 2009; Koopman et al., 2011; Shimizu et al., 2012; Padro and Sanders, 2014), but pro-inflammatory roles are proposed in some other target tissues, or at later time points in the course of several chronic pain conditions (Härle et al., 2005; Bellinger et al., 2008; Benarroch, 2009). Many of these studies focused on catecholamines and ignored sympathetic cotransmitters. In vitro studies of sympathetic transmitter effects on immune cells also support both pro-inflammatory and antiinflammatory effects depending on the transmitter or receptor studied and the conditions (Haskó, 2001; Kin and Sanders, 2006; Straub et al., 2006; Koopman et al., 2011; Pongratz and Straub, 2013; Schlereth et al., 2014). These conflicting reports make it difficult to interpret experiments testing effects of more global surgical or chemical methods of sympathectomy on chronic pain models.

Local DRG inflammation is important in some forms of low back pain. In preclinical back pain models, signs of inflammation include invasion of the DRG by immune cells, activation of the satellite glia, upregulation of pro-inflammatory cytokines, and downregulation of anti-inflammatory cytokines (Kawakami et al., 1996; Murata et al., 2006b; Xie et al., 2006; Sasaki et al., 2007; Amaya et al., 2009; Otoshi et al., 2010; Huang et al., 2011; Watanabe et al., 2011; de Souza Grava et al., 2012). However, DRG inflammation also plays a role in neuropathic pain models that involve axon damage or transection, especially during the early phase. This is very evident in the spinal nerve ligation model, a commonly used model of neuropathic pain in which the injury is very close to the DRG. Neuropathic pain models involving more remote injury can also lead to DRG inflammation, including the chronic constriction injury, sciatic nerve transection, and spared nerve injury models (Hu and McLachlan, 2002; Wang et al., 2002; Moalem et al., 2004; McLachlan and Hu, 2014).

Many previous studies used methods of sympathectomy (chemical or surgical) that may have widespread effects. In this study, we used a "microsympathectomy" (mSYMPX) method, cutting the gray rami to the L4 and L5 DRG, removing sympathetic postganglionic fibers from those DRG and hindlimb regions innervated by the L4 and L5 spinal nerves, but leaving innervation of spleen, thymus, and many other organs generally intact. We report that this gives large reductions in mechanical pain behaviors, neuronal hyperexcitability, and the pro-inflammatory cytokine profile induced by local DRG inflammation, a rat model of radicular back pain, as well as reduced inflammation and pain behavior in the peripheral inflammation model induced by paw injection of complete Freund's adjuvant (CFA).

\section{Materials and Methods}

Animals. The experimental protocol was approved by the Institutional Animal Care and Use Committee of the University of Cincinnati. Experiments were conducted in accordance with the National Institutes of
Table 1. Full, systemic, and alternative names of cytokines examined

\begin{tabular}{|c|c|c|}
\hline Name in text & Full name & Alternative and systemic names \\
\hline EGF & Epidermal growth factor & \\
\hline Eotaxin & Eotaxin & CLL1 \\
\hline Fractalkine & Fractalkine & CX3CL1 \\
\hline GRO/KC & $\begin{array}{l}\text { Growth-related oncogene/ } \\
\text { keratin-derived chemokine }\end{array}$ & $\begin{array}{l}\text { CXCL1; CINC-1; plays a role similar to } \\
\text { human IL-8 }\end{array}$ \\
\hline IFN $\gamma$ & Interferon $\gamma$ & \\
\hline IL-10 & Interleukin-10 & Cytokine synthesis inhibitory factor \\
\hline IL-12p70 & Interleukin-12 & p70 refers to the active heterodimer \\
\hline IL-18 & Interleukin 18 & Interferon-gamma inducing factor \\
\hline IL-1 $\alpha$ & Interleukin $1 \alpha$ & \\
\hline IL-1 $\beta$ & Interleukin $1 \beta$ & \\
\hline IL-2 & Interleukin-2 & \\
\hline IL-4 & Interleukin-4 & \\
\hline IL-6 & Interleukin-6 & \\
\hline $\mid \mathrm{P}-10$ & $\begin{array}{l}\text { Interferon } \gamma \text {-induced } \\
\quad \text { protein } 10\end{array}$ & CXCL10 \\
\hline Leptin & Leptin & Ob gene \\
\hline MCP-1 & $\begin{array}{l}\text { Monocyte chemotactic } \\
\text { protein } 1\end{array}$ & $\mathrm{CCL} 2$ \\
\hline MIP-1 $\alpha$ & $\begin{array}{l}\text { Macrophage inflammatory } \\
\quad \text { protein } 1 \alpha\end{array}$ & $\mathrm{CCL} 3$ \\
\hline MIP-2 & $\begin{array}{l}\text { Macrophage inflammatory } \\
\text { protein } 2\end{array}$ & CXCL2 \\
\hline RANTES & $\begin{array}{l}\text { Regulated on activation, } \\
\text { normal T-cell expressed and } \\
\text { secreted }\end{array}$ & $\mathrm{CCL} 5$ \\
\hline $\operatorname{TNF} \alpha$ & Tumor necrosis factor $\alpha$ & \\
\hline VEGF & Vascular endothelial growth factor & \\
\hline
\end{tabular}

Health Guide for the Care and Use of Laboratory Animals. Sprague Dawley rats of both sexes (Harlan), weighing 100-120 g at the time of first surgery, were used as indicated. Our prior study showed female and male behavioral responses to the DRG inflammation model were very similar (Xie et al., 2013). Rats were housed two same-sex rats per cage at $22 \pm$ $0.5^{\circ} \mathrm{C}$ under a controlled diurnal cycle of $14 \mathrm{~h}$ light and $10 \mathrm{~h}$ dark.

Surgical procedure for local inflammation of the DRG (LID). The surgery was performed as previously described (Xie et al., 2012b). Briefly, under isoflurane anesthesia, an incision was made along the spine and the L5 intervertebral foramen was visualized by exposing L5 and L4 transverse processes by separating the overlying back spine paraspinal muscles. No laminectomy was performed. The immune activator zymosan (SigmaAldrich, catalog \#Z4250, $10 \mu \mathrm{l}$ of $2 \mathrm{mg} / \mathrm{ml}$ in incomplete Freund's adjuvant) was injected into the L5 intervertebral foramen, above the DRG, via a 1/2" 30 gauge needle bent at a 90 degree angle inserted into the L5 intervertebral foramen. For experiments in which DRGs were collected for protein isolation or electrophysiological experiments, both L4 and L5 were inflamed. This method of DRG inflammation is less invasive than our originally published description of this model (Xie et al., 2006), which involved drilling a small hole into the bone overlying the DRG.

Procedure for localized paw inflammation with CFA. CFA (SigmaAldrich, catalog \#F5881, containing $1 \mathrm{mg} / \mathrm{ml}$ of Mycobacterium tuberculosis, heat killed and dried, in $85 \%$ paraffin oil and $15 \%$ mannide monooleate) was diluted with an equal volume of ACSF (formulation below). Under brief isoflurane anesthesia, $50 \mu \mathrm{l}$ of the mixture was injected subcutaneously into the heel region of one paw using an $8 \mathrm{~mm} 31$ gauge needle. For comparison, a dose of $150 \mu \mathrm{l} \mathrm{CFA} \mathrm{at} 1 \mathrm{mg} / \mathrm{ml}$ was shown to cause only local tissue and joint inflammation, with arthritic changes in only the local joints and seen only at later times (e.g., $30 \mathrm{~d}$ ) (Almarestani et al., 2011) than we studied in our experiments, whereas higher doses (e.g., $5 \mathrm{mg} / \mathrm{ml}$ ) are required to elicit systemic inflammation and arthritic changes in more distant and contralateral joints (Donaldson et al., 1993).

Surgical procedure for local mSYMPX. Before or after the pain model surgeries, as indicated, the proximal L4 and L5 spinal nerves and transverse processes were exposed. The spinal nerves (ventral rami) were vi- 
sualized and freed from surrounding tissue. The gray rami entering the L4 and L5 spinal nerves close to the DRGs (i.e., coming from the L3 and L4 sympathetic paravertebral ganglia according to the nomenclature of Baron et al., 1988) were identified on the ventral side of the spinal nerve at the position very close to the intervertebral foramen. At this site, where the gray ramus merges into the spinal nerve just across from the juncture where the dorsal ramus diverges from the ventral ramus (see Fig. 1 ), the gray rami and nearby connective tissue were gently dissected away from the nearby blood vessels and cut and disconnected from spinal nerve. Approximately $1 \mathrm{~mm}$ of gray ramus was further removed to make a gap and slow regeneration. Both L4 and L5 gray rami were cut in all mSYMPX surgeries, even though only the L5 DRG was inflamed in LID surgeries, because our previous study showed that there was possible spread of the zymosan solution into the ipsilateral L4 spinal nerve (Xie et al., 2006). Sham controls received similar exposure of the spinal nerves, but the gray rami were not cut.

Anatomical studies indicate this mSYMPX procedure should spare the sympathetic innervation of regions not innervated by the L4 and L5 spinal nerves, including most primary immune tissues, adrenals, and organs innervated by the mesenteric ganglia (Baron et al., 1988; Nance and Burns, 1989), although denervation of some secondary immune tissue (e.g., draining lymph nodes) is likely. Sympathetic nerves may also regulate hematopoiesis in the bone marrow (Bellinger et al., 2008). The primary sites of hematopoiesis in rats are the sternum, rib, humerus, femur, and proximal tibia, whereas the distal tibia does not contribute (Cline and Maronpot, 1985). Although many of these sites should have been unaffected by the mSYMPX procedure, hematopoiesis at ipsilateral sites in the leg bones may also have been affected by the mSYMPX procedure.

Immunohistochemical staining for tyrosine hydroxylase (TH) $7 \mathrm{~d}$ after mSYMPX confirmed the loss of TH-positive fibers in the DRG and surrounding capsule ( $n=6$ male mSYMPX animals and 6 male sham mSYMPX animals), and in the region of the paw where CFA was injected ( $n=4$ male sham mSYMPX and 4 male mSYMPX rats). Additional staining in the paw region $28 \mathrm{~d}$ after the mSYMPX and $14 \mathrm{~d}$ after CFA inflammation (corresponding to the final behavioral time point measured in the CFA model) did not reveal any recovery or sprouting from adjacent areas of TH-positive fibers into the region used for behavioral testing ( $n=4$ male animals per group). For comparison, sympathetic sprouting in the skin in the (low dose) CFA model develops slowly and was significant only at 4 weeks (Almarestani et al., 2008).

Behavior testing. Mechanical sensitivity was tested by applying a series of von Frey filaments to the heel region of the paws, using the up-anddown method (Chaplan et al., 1994). A cutoff value of $15 \mathrm{~g}$ was assigned to animals that did not respond to the highest filament strength used. A fine wisp of cotton was stroked mediolaterally across the plantar surface of the hindpaws to score the presence or absence of a brisk withdrawal response to a normally innocuous mechanical stimulus (light touchevoked tactile allodynia). This stimulus does not evoke a response in normal animals. Cold sensitivity (cold allodynia) was scored as withdrawal responses to a drop of acetone applied to the ventral surface of the hindpaw. When observed, responses to acetone or light brush strokes consisted of several rapid flicks of the paw and/or licking and shaking of the paw; walking movements were not scored as positive responses. Hypersensitivity to thermal (heat) stimuli was not examined because we have previously observed that this is little affected by LID (Xie et al., 2006).

Electrophysiology. Intracellular recording in current-clamp mode was performed at $36^{\circ} \mathrm{C}-37^{\circ} \mathrm{C}$ using microelectrodes in sensory neurons near the dorsal surface of an acutely isolated whole DRG preparation, as previously described (Xie et al., 2012b). This preparation allows neurons to be recorded without enzymatic dissociation, with the surrounding satellite glia cells and neighboring neurons intact (Song et al., 1999; Zhang et al., 1999). The DRG was continuously perfused with ACSF (in mM) as follows: $\mathrm{NaCl} 130, \mathrm{KCl} 3.5, \mathrm{NaH}_{2} \mathrm{PO}_{4} 1.25, \mathrm{NaHCO}_{3} 24$, dextrose 10, $\mathrm{MgCl}_{2} 1.2, \mathrm{CaCl}_{2}$ 1.2, HEPES 16, pH 7.3 (bubbled with $95 \% \mathrm{O}_{2} / 5 \%$ $\mathrm{CO}_{2}$ ). Cells were classified by conduction velocity (stimulation of attached dorsal root) as follows: $<1.2 \mathrm{~m} / \mathrm{s}, \mathrm{C}$; $\geq 7.5 \mathrm{~m} / \mathrm{s}, \mathrm{A} \beta$; between 1.2 and $7.5 \mathrm{~m} / \mathrm{s}, \mathrm{A} \delta$ (Stebbing et al., 1999). Excitability parameters were analyzed as described previously (Xie et al., 2015). Data from recorded cells were pooled for each group of rats.

$D R G$ and paw skin histology. Animals were first perfused with $0.1 \mathrm{M}$ phosphate buffer until clear fluid was seen, followed by perfusion with $4 \%$ PFA for $20 \mathrm{~min}$. Standard H\&E staining was used to verify histological 


\section{Females}

A
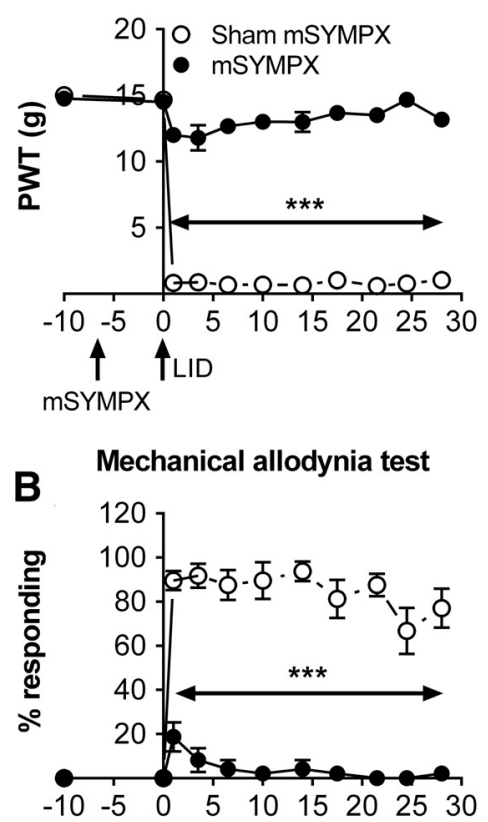

C Acetone test

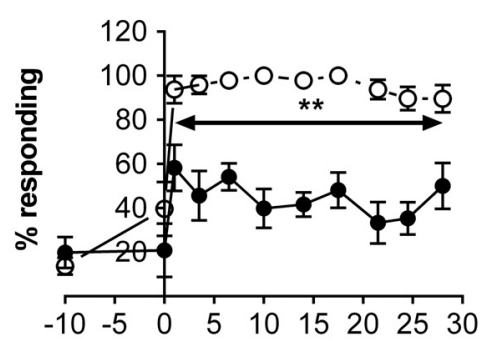

Males
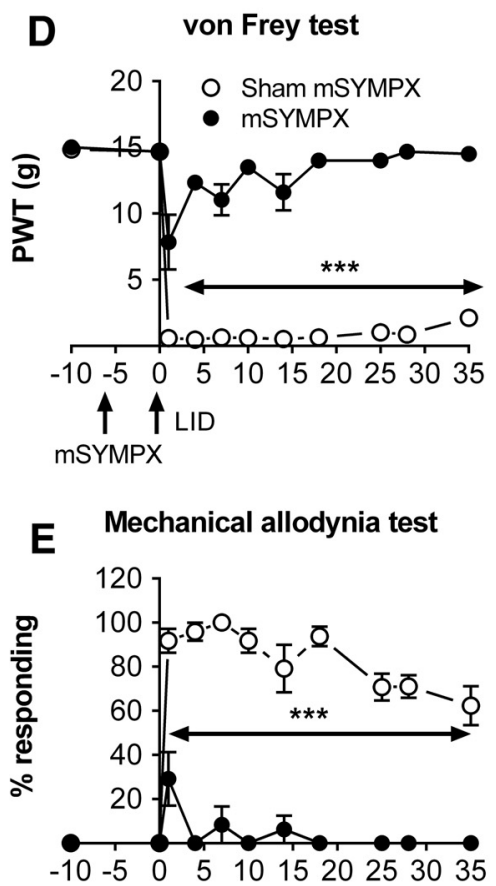

$\mathbf{F}$

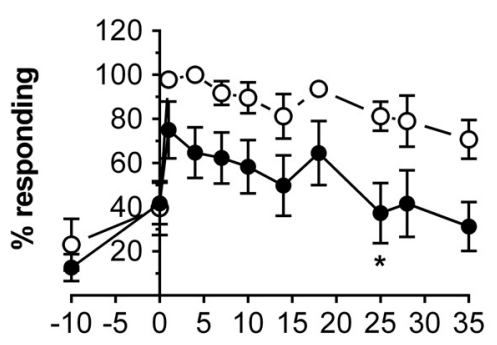

Days after LID

Figure 2. Effect of prior mSYMPX on pain behaviors induced by local DRG inflammation is similar in both sexes. Behaviors were measured before any surgery, and the average baseline is plotted on POD - 10. A first surgery was performed to cut the gray rami to the ipsilateral L4 and L5 (mSYMPX) or the corresponding sham surgery. Behavior was measured again 3-10 d later; no effects of mSYMPX or sham mSYMPX on baseline behaviors were observed (data plotted on day 0 ). After this behavior measurement, on POD 0 , a second surgery was performed to locally inflame the L5 DRG (LID). $A, D$, Paw withdrawal threshold (PWT) to von Frey stimuli was reduced by LID but remained near baseline in LID + $\mathrm{mSYMPX}$ animals. $\boldsymbol{B}, \boldsymbol{E}$, Mechanical allodynia(withdrawal response to light stroking with a cotton wisp) was significantly increased by LID but largely absent in the MSYMPX group. C, F, Cold allodynia (withdrawal responses to a drop of acetone on the paw) was increased by LID and significantly reduced by mSYMPX on the indicated days. ${ }^{*} p<0.05 ;{ }^{* *} p<0.01 ;{ }^{* * *} p<0.001$, significant difference between LID + sham mSYMPX and LID + mSYMPX groups at indicated time points (two-way repeated-measures ANOVA with Tukey's post hoc test). Left, Female rats, $N=8$ per group; experimenter was blinded as to the sham/mSYMPX status. Right, Male rats, $N=8$ per group.

features of paw skin inflammation. Paw sections ( $4 \mu \mathrm{m}$, paraffin embedded) were cut and processed for H\&E staining by the Pathology Research Core at the Cincinnati Children's Hospital Medical Center, Cincinnati. For immunohistochemistry, paw skin or DRG sections were cut at $40 \mu \mathrm{m}$ on a cryostat after fixation in $4 \%$ PFA, $0.1 \mathrm{~m}$ phosphate buffer, $4 \%$ sucrose. The TH antibody was from Pel-Freez (catalog \#P40101-150), diluted 1:500. The Iba-1 antibody was from Abcam (catalog \#ab5076), diluted 1:500. For quantification of Iba-1 staining, images from multiple sections of each DRG or paw, selected at random, were captured under an Olympus BX61 fluorescent microscope using Slidebook 4.1 imaging acquisition software (Intelligent Imaging Innovation), and intensity of signal was normalized by cellular area (DRG) or the dermis area (paw). For quantification of immunohistochemical staining, all image capture and analysis sessions were performed comparing samples from all experimental groups, prepared with the same staining solutions, then measured using identical display parameters.

Multiplex cytokine measurement. Cytokine expression profiles were evaluated using a BioPlex System (Bio-Rad) combined with Millipore Rat Cytokine/Chemokine Magnetic Bead Panel (catalog \#RECYMAG65K27PMX, EMD Millipore). A total of 21 rat cytokines was measured simultaneously from a single well according to the manufacturer's protocols and as in our previous study (Xie et al., 2006). Full names, systemic names, and alternative names of the cytokines examined are given in Table 1 . Inflamed DRGs, with mSYMPX or sham mSYMPX performed $7 \mathrm{~d}$ before DRG inflammation, were obtained on $1,3,7$, or $14 \mathrm{~d}$ after DRG inflammation under isoflurane anesthesia. Control DRGs were obtained from normal rats. DRGs were suspended in $100 \mu \mathrm{l}$ of icecold lysis buffer: $50 \mathrm{~mm}$ Tris, $5 \mathrm{~mm}$ EDTA, pH 7.5, $1 \%$ Triton X-100 and protease inhibitor mixture (Complete, EDTA-free, Roche Diagnostics). The tissues were homogenized with a homogenizer and centrifuged $1 \mathrm{~h}$ at $57,000 \times g$, at $4^{\circ} \mathrm{C}$. The protein concentration was measured and lysates were stored at $-80^{\circ} \mathrm{C}$ until analysis. Protein samples $(25 \mu \mathrm{l}$ of the above supernatant) were run in duplicate and the values averaged. Antibody-coupled beads were incubated with the tissue sample (antigen) after which they were incubated with biotinylated detection antibody before finally being incubated with the reporter molecule streptavidin-PE conjugate. A broad sensitivity range of standards covering a 4000- to 5000fold range was used to quantify over a wide range of cytokine concentrations. This captured immunoassay was then read by the BioPlex System which uses Luminex fluorescent bead-based technology (Luminex). This method has sensitivity and performance similar to ELISA methods but requires much smaller sample volumes and is suitable for multiplexing (duPont et al., 2005).

Paw measurements. Under brief isoflurane anesthesia, the width and height of each hindpaw around the heel were measured with calipers. The height (thickness) was measured by placing the one caliper on the top of the foot directly against the ankle, and the other caliper on the bottom of the foot at the heel. The width was measured at the point of widest medial-lateral distance, which was always near the heel. The two dimensions (average of 3 measurements each) were multiplied together to give a measure of paw cross-sectional area. Ipsilateral area was normalized to contralateral area to give an index of the amount of paw swelling.

Statistics and data analysis. Behavioral data presented are all from the ipsilateral side; as in previous studies with the LID and low-dose CFA models, the contralateral behaviors showed no or relatively small changes from baseline (data not shown). Two-sided statistical tests were used throughout. Behavioral time course data were analyzed using two-way repeatedmeasures ANOVA with Bonferroni post hoc test to determine on which days experimental groups differed. Within each experimental group, one-way ANOVA with Dunnett's post hoc test was used to determine on which day behavioral measurements differed from baseline. For cytokine data, fold 
changes in concentrations of cytokine normalized by protein content were compared using a ratio $t$ test (i.e., a $t$ test on the log-transformed values). For the log transform, concentrations detected by the software as being out of range (low) were set equal to the lowest detectable concentration as specified by the detection kit manufacturer instead of being set to zero. For immunohistochemical quantification, values obtained from multiple images from each rat were averaged, and the statistical analysis was conducted on these averages using the number of rats as the $N$ value for each group. For experiments where 3 experimental groups were compared with ANOVA, post hoc tests comparing each group to every other group were used. For electrophysiological data, comparison of values between different experimental groups was done using nonparametric methods for data that did not show a normal distribution based on the D'Agostino and Pearson omnibus normality test. The statistical test used in each case is indicated in the text, or figure legend. Significance was ascribed for $p<0.05$. Data are presented as mean \pm SEM.

\section{Results}

Surgical or chemical sympathectomy is expected to have widespread effects on many physiological systems throughout the body. To examine only effects of local sympathectomy on nociception, we developed a method we term "microsympathectomy" (mSYMPX), in which the gray rami to the spinal nerves close to the ipsilateral L4 and L5 DRGs were cut (Fig. 1).

Prior mSYMPX blocked mechanical pain behaviors induced by local DRG inflammation

In the first set of experiments, the effect of mSYMPX before LID was examined. Although we previously observed that both male and female rats had similar responses to LID, it was not known whether both would have similar responses to mSYMPX. Recent work (Mogil, 2012) has emphasized the importance of including both sexes in preclinical biomedical research, especially in the pain field in which research on males has long predominated. Therefore, in this experiment, both sexes were tested and the data for each sex are presented separately.

After baseline behavior measurements, animals underwent a first surgery to implement the mSYMPX; control animals received a sham surgery with similar exposure of the ganglia but without cutting the gray rami. Before implementing the pain model, mSYMPX did not affect baseline pain behaviors (Fig. 2). Animals then underwent a second surgery in which
A

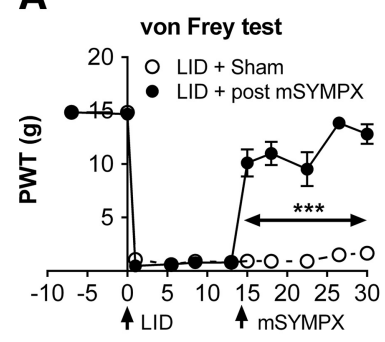

B

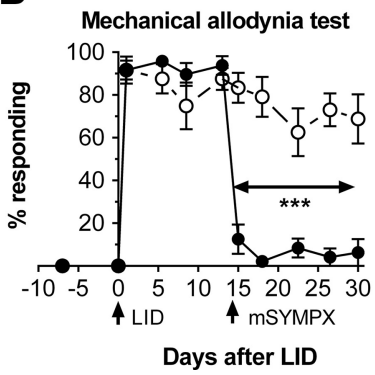

C

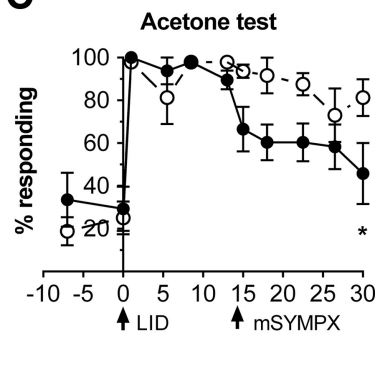

Figure 3. Effect of mSYMPX on established pain behaviors in the local DRG inflammation model. Two baseline pain measurements were obtained (plotted on POD -7 and POD 0). On POD 0, the L5 DRG was inflamed. On POD 14, a second surgery was

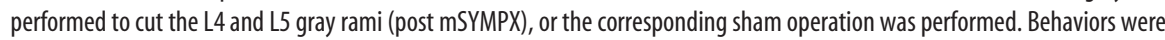
measured on POD 13 just before and POD 15 just after the second surgery. Post mSYMPX rapidly ameliorated the decreased von Frey threshold $(\boldsymbol{A})$ and the increased response to light strokes $(\boldsymbol{B})$. Effects on cold allodynia $(\boldsymbol{C})$ were less marked. ${ }^{*} p<0.05{ }^{* * * *} p<$ 0.001 , significant difference between the two groups at indicated time points (two-way repeated-measures ANOVA with Bonferroni post hoc test). $N=8$ male rats per group. Experimenter was blinded starting on POD 14 as to the mSYMPX/Sham status. PWT, Paw withdrawal threshold.
A

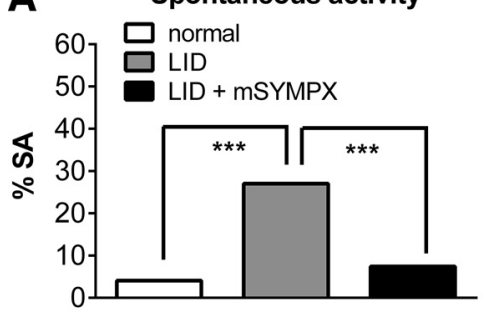

C

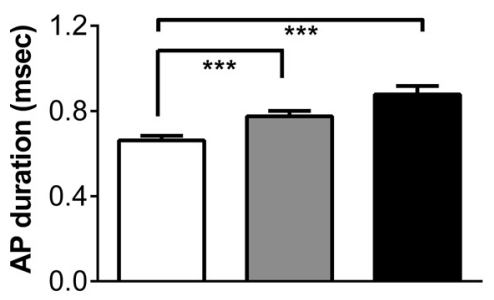

E

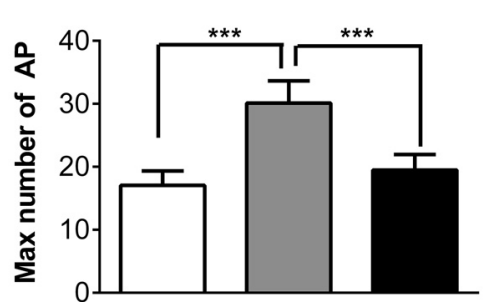

B

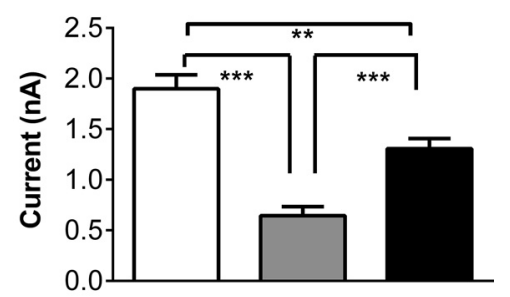

D

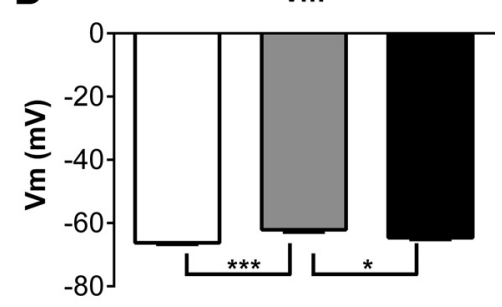

$\mathbf{F}$

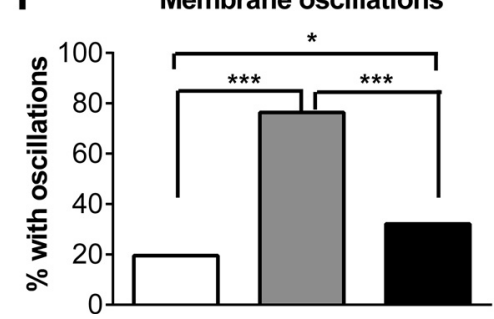

Figure 4. mSYMPX reduces hyperexcitability of A $\beta$ neurons induced by local DRG inflammation. mSYMPX was performed 5-7 $\mathrm{d}$ before local DRG inflammation (LID). Microelectrode recordings were made in isolated L5 DRG $4 \mathrm{~d}$ after local inflammation. Data are compared with contemporaneous recordings in control and inflamed L5 DRG from our recent publication (Xie et al., 2016); these DRGs also received injection of a control siRNA, which we have found does not affect the electrophysiological or behavioral responses. In the control group, the injection of control siRNA involved surgical exposure of the DRG, serving as a sham control for the LID surgery. All data are from $A \beta$ neurons as classified by dorsal root conduction velocity. $A$, Spontaneous activity was increased by LID and normalized by prior mSYMPX. B, Rheobase was reduced by LID and partially normalized by mSYMPX. C, Action potential (AP) duration was increased by LID but not affected by mSYMPX. D, Resting membrane potential was depolarized by LID and normalized by mSYMPX. In response to suprathreshold currents, the maximum number of action potentials that could be evoked $(\boldsymbol{E})$ and the percentage of cells able to exhibit subthreshold membrane oscillations $(\boldsymbol{F})$ were increased by LID and completely $(\boldsymbol{E})$ or partially $(\boldsymbol{F})$ normalized by mSYMPX. ${ }^{*} p<0.05 ;{ }^{* *} p<0.01 ;{ }^{* * *} p<0.001$; significant difference between the indicated groups $\left(\boldsymbol{A}, \boldsymbol{F}, \chi^{2}\right.$ test; $\boldsymbol{B}, \boldsymbol{C}, \boldsymbol{E}, \mathrm{Kruskal}-$ Wallis test with Dunn's posthoctest; $\boldsymbol{D}$, one-way ANOVA with Bonferroni's posthoctest). Each group was compared with every other group in the post hoc tests; comparisons with no significance symbol indicated were not statistically significant. $N=123$ normal cells from 4 female rats, 74 LID cells from 3 female rats, and 135 LID + mSYMPX cells from 6 female rats. 
the L5 DRG was inflamed by applying the immune stimulator zymosan in incomplete Freund's adjuvant. As in our previous studies (Xie et al., 2006, 2012a, b, 2013, 2016) and in control animals receiving no first surgery (data not shown), DRG inflammation in animals receiving sham mSYMPX led to rapid, marked decreases in the mechanical threshold as measured by responses to von Frey filaments and increased mechanical allodynia as measured by responses to stroking with a cotton wisp, a stimulus that never evokes a withdrawal response in normal animals. However, in the animals receiving mSYMPX before DRG inflammation, these pain behaviors were significantly reduced compared with the sham mSYMPX + LID group at all time points tested (Fig. 2). The effect was large; within either the male or female mSYMPX + LID groups, the mechanical sensitivity did not differ from baseline $(P O D-10)$ at any time point later than POD 7 (von Frey test) or POD 1 (mechanical allodynia test). In contrast, in animals of either sex, mechanical behaviors remain significantly different from baseline after LID + sham mSYMPX (Fig. 2) for $>4$ weeks (duration of the experiment).

Cold allodynia, measured as withdrawal responses to a drop of acetone applied to the paw, also increased after DRG inflammation, but the effect of mSYMPX was less marked. In females, cold responses were significantly reduced by MSYMPX on all days tested when comparing the MSYMPX group with the sham mSYMPX group (two-way repeated-measures ANOVA). However, within the female mSYMPX group, one-way ANOVA comparing the value at baseline to that on subsequent days showed that cold responses still remained significantly higher than baseline on most days. In males, the reduction in cold responses after MSYMPX was somewhat smaller: the difference between the MSYMPX and sham SYMPX groups reached significance on only $1 \mathrm{~d}$ (Fig. 2; two-way repeatedmeasures ANOVA).

The similarity of cold and mechanical responses between males and females in response to the LID surgery in the absence of mSYMPX is as we previously reported in this model (Xie et al., 2013).

We also observed similarly large effects of prior mSYMPX on mechanical behaviors using a different back pain model, chronic compression of the DRG (data not shown; the "CCD" model used was as originally described by Song et al., 1999; Zhang et al., 1999).

mSYMPX after pain was established reversed mechanical pain behaviors induced by local DRG inflammation

To determine whether mSYMPX also reduced established pain behaviors, animals underwent DRG inflammation followed $14 \mathrm{~d}$ later by a second surgery (mSYMPX or sham mSYMPX). As shown in Figure 3, mSYMPX but not sham mSYMPX markedly reduced mechanical pain behaviors, an effect that was observed as early as $1 \mathrm{~d}$ after the mSYMPX surgery. After the second surgery, differences between the two groups were significant for the rest of the experiment (two-way repeated-measures ANOVA). Within the mSYMPX group, one-way ANOVAs comparing later time points to the baseline showed that the von Frey threshold eventually (last 2 time points) did not differ significantly from baseline; for the mechanical allodynia test, the values did not differ significantly from baseline at any point after the mSYMPX surgery. As for the data with prior mSYMPX, post mSYMPX had more modest effects on cold allodynia; although one-way ANOVA within the mSYMPX group comparing later time points with baseline showed that cold responses did not differ significantly from baseline after the second surgery, two-way repeatedmeasures ANOVA showed that the differences between the two
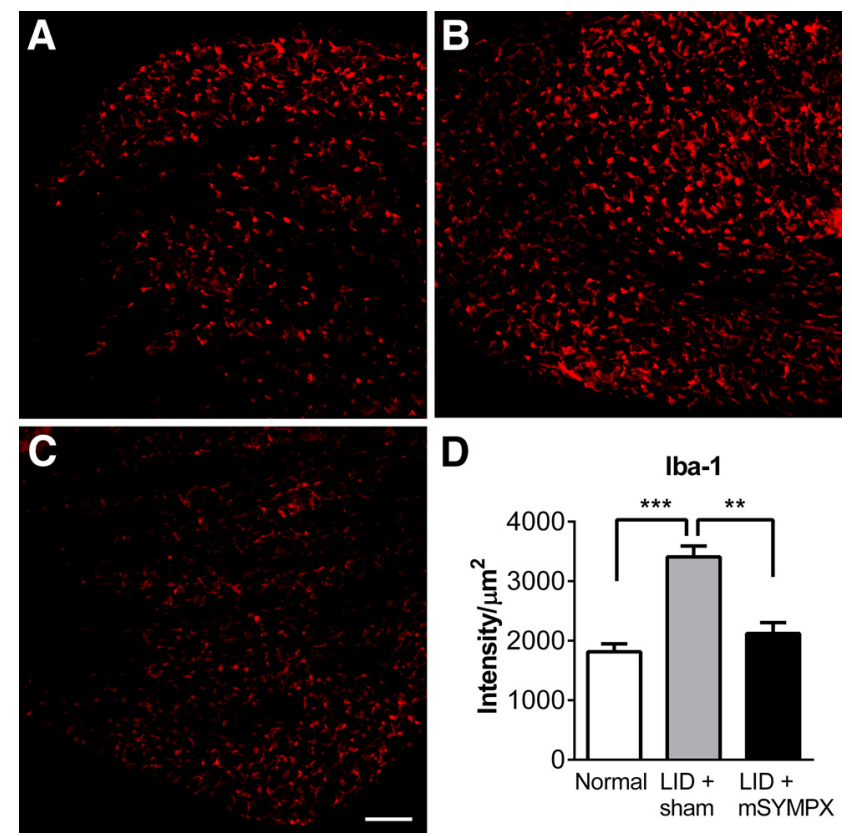

Figure 5. mSYMPX reduces macrophage staining in the inflamed DRG. DRG sections were obtained from normal animals, or obtained $4 \mathrm{~d}$ after DRG inflammation (LID), which was performed $7 \mathrm{~d}$ after mSYMPX or sham MSYMPX surgery. Red staining represents macrophage marker Iba-1. $\boldsymbol{A}$, Example of Iba-1 staining in cellular areas in normal DRG. $\boldsymbol{B}$, Example of inflamed DRG with prior sham mSYMPX. C, Example of inflamed DRG with prior mSYMPX. $\boldsymbol{D}$, Summary data of Iba- 1 intensity normalized to area of the DRG measured; only areas containing neuronal cell bodies were included in the analysis and examples shown are from cellular areas. ${ }^{* *} p<0.01 ;{ }^{* * *} p<0.001$, significant difference between indicated groups (ANOVA with Tukey's post hoc test). The normal and LID + mSYMPX groups did not differ significantly from each other. $N=4$ rats per group, equal numbers of male and female rats, $19-28$ sections per animal.

groups were not significant at any time point, except for the last day of testing.

Prior mSYMPX reduced hyperexcitability of myelinated sensory neurons induced by local DRG inflammation

We have previously shown that local DRG inflammation leads to marked hyperexcitability in myelinated $\mathrm{A} \beta$ cells in the inflamed DRG, as measured on POD 4 (Xie et al., 2006). The most striking changes are increased spontaneous activity and ability to fire repetitively, and decreased rheobase. These changes correlate well with establishment of mechanical pain behaviors over several manipulations (Xie et al., 2005, 2012b, 2013). Microelectrode recordings made in an isolated whole DRG preparation $4 \mathrm{~d}$ after DRG inflammation showed that the excitability changes induced by DRG inflammation were reduced or blocked by mSYMPX performed 5-7 d before the DRG inflammation (Fig. 4). Spontaneous activity was increased by LID and normalized by mSYMPX. The marked decrease in rheobase induced by LID was partially normalized by mSYMPX. Similar results were obtained when spontaneously active cells (rheobase defined as zero) were omitted from the analysis (data not shown). The rheobase change did not reflect changes in input resistance, which did not differ between any of the 3 groups (normal, $16.3 \pm 1.0 \mathrm{M} \Omega$; LID, $17.0 \pm$ $0.8 \mathrm{M} \Omega$; LID + mSYMPX, $16.5 \pm 0.75 \mathrm{M} \Omega$; Kruskal-Wallis test). Action potentials were slightly broadened by LID, but this was observed in both the mSYMPX and sham mSYMPX groups; in the latter two groups, the action potential widths did not differ significantly from each other. The membrane depolarization induced by LID was normalized by mSYMPX. The maximum 
Table 2. Effect of mSYMPX on cytokine profiles after local DRG inflammation ${ }^{a}$

\begin{tabular}{|c|c|c|c|c|c|c|}
\hline & Cytokine & $\begin{array}{l}\text { Concentration in } \\
\text { normal DRG }\end{array}$ & $\begin{array}{l}\text { POD } 1 \text { fold changec } \\
\text { LID; LID + mSYMPX }\end{array}$ & $\begin{array}{l}\text { POD } 3 \text { fold change } \\
\text { LID; LID + mSYMPX }\end{array}$ & $\begin{array}{l}\text { POD } 7 \text { fold change } \\
\text { LID; LID + mSYMPX }\end{array}$ & $\begin{array}{l}\text { POD } 14 \text { fold change } \\
\text { LID; LID + mSYMPX }\end{array}$ \\
\hline \multirow[t]{8}{*}{ Group 1} & \multirow[t]{2}{*}{ IL-2 } & \multirow[t]{2}{*}{$0.14 \pm 0.04$} & $0.29 \pm 0.1^{* \#}$ & $0.14 \pm 0.1^{* \text { *\# }}$ & $0.19 \pm 0.1^{* \# \#}$ & $0.26 \pm 0.2^{*}$ \\
\hline & & & $1.07 \pm 0.4$ & $1.05 \pm 0.4$ & $0.71 \pm 0.3$ & $1.10 \pm 0.7$ \\
\hline & \multirow[t]{2}{*}{ IL-12p70 } & \multirow[t]{2}{*}{$0.85 \pm 0.12$} & $0.60 \pm 0.1$ & $0.23 \pm 0.1^{* \text { *\# }}$ & $0.40 \pm 0.1^{*}$ & $0.43 \pm 0.1^{*}$ \\
\hline & & & $1.08 \pm 0.3$ & $0.67 \pm 0.1$ & $0.52 \pm 0.1^{*}$ & $0.68 \pm 0.3$ \\
\hline & \multirow[t]{2}{*}{ Eotaxin } & \multirow[t]{2}{*}{$0.30 \pm 0.04$} & $0.59 \pm 0.1^{* \#}$ & $0.40 \pm 0.1^{* * \#}$ & $0.38 \pm 0.1^{* * \# \#}$ & $0.47 \pm 0.1^{*}$ \\
\hline & & & $1.07 \pm 0.1$ & $1.10 \pm 0.2$ & $0.81 \pm 0.0$ & $0.97 \pm 0.2$ \\
\hline & \multirow[t]{2}{*}{$\mathrm{IL}-4$} & \multirow[t]{2}{*}{$0.36 \pm 0.04$} & $0.97 \pm 0.6$ & $0.38 \pm 0.2^{* \#}$ & $0.41 \pm 0.2^{*}$ & $0.29 \pm 0.1^{* \# \#}$ \\
\hline & & & $1.24 \pm 0.1$ & $1.05 \pm 0.2$ & $0.55 \pm 0.1^{* *}$ & $0.84 \pm 0.2$ \\
\hline \multirow[t]{10}{*}{ Group 2} & \multirow[t]{2}{*}{ MCP-1 } & \multirow[t]{2}{*}{$2.84 \pm 0.21$} & $5.1 \pm 0.6^{* * * \#}$ & $3.6 \pm 0.4^{* * * \# \#}$ & $3.0 \pm 0.5^{* * * \#}$ & $1.9 \pm 0.3^{*}$ \\
\hline & & & $2.8 \pm 0.5^{* * *}$ & $1.9 \pm 0.2^{* *}$ & $1.5 \pm 0.2$ & $1.1 \pm 0.2$ \\
\hline & \multirow[t]{2}{*}{ IL-6 } & \multirow[t]{2}{*}{$1.83 \pm 0.37$} & $11.0 \pm 3.0^{* * *}$ & $3.9 \pm 1.1^{* * \#}$ & $1.4 \pm 0.3$ & $0.7 \pm 0.2$ \\
\hline & & & $5.2 \pm 0.9^{* *}$ & $1.6 \pm 0.1$ & $1.3 \pm 0.3$ & $1.0 \pm 0.5$ \\
\hline & \multirow[t]{2}{*}{$\mathbb{I L}-1 \alpha$} & \multirow[t]{2}{*}{$0.53 \pm 0.27$} & $10.8 \pm 2.6^{* * \# \#}$ & $21.2 \pm 10.7^{* * \# \#}$ & $10.5 \pm 2.6^{* * \#}$ & $3.0 \pm 0.9$ \\
\hline & & & $2.1 \pm 0.5$ & $2.6 \pm 0.5^{*}$ & $2.8 \pm 0.8$ & $1.6 \pm 0.7$ \\
\hline & \multirow[t]{2}{*}{ MIP-2 } & \multirow[t]{2}{*}{$0.47 \pm 0.09$} & $14.7 \pm 4.4^{* * *}$ & $7.7 \pm 3.6^{*}$ & $1.7 \pm 0.2$ & $1.4 \pm 0.4$ \\
\hline & & & $6.2 \pm 2.8^{*}$ & $1.4 \pm 0.2$ & $1.2 \pm 0.2$ & $1.2 \pm 0.4$ \\
\hline & \multirow[t]{2}{*}{ GRO/KC } & \multirow[t]{2}{*}{$1.87 \pm 0.39$} & $4.9 \pm 3.5$ & $3.5 \pm 2.6$ & $2.0 \pm 0.9$ & $0.7 \pm 0.1$ \\
\hline & & & $1.3 \pm 0.3$ & $1.1 \pm 0.3$ & $0.8 \pm 0.1$ & $1.0 \pm 0.3$ \\
\hline \multirow[t]{6}{*}{ Group 3} & \multirow[t]{2}{*}{ IL-18 } & \multirow[t]{2}{*}{$3.53 \pm 0.42$} & $2.5 \pm 0.3^{* *}$ & $5.6 \pm 0.2^{* * * \# \# \#}$ & $5.8 \pm 0.3^{* * *}$ & $5.7 \pm 1.0^{* * * \#}$ \\
\hline & & & $1.8 \pm 0.3^{*}$ & $3.2 \pm 0.1^{* * *}$ & $4.1 \pm 0.9^{* *}$ & $2.6 \pm 0.8^{*}$ \\
\hline & \multirow[t]{2}{*}{ MIP-1 $1 \alpha$} & \multirow[t]{2}{*}{$0.05 \pm 0.01$} & $48.2 \pm 13.1^{* * *}$ & $37.4 \pm 8.8^{* * * \#}$ & $33.0 \pm 4.9^{* * *}$ & $30.0 \pm 7.1^{* * * \#}$ \\
\hline & & & $20.0 \pm 8.3^{* *}$ & $11.8 \pm 4.0^{* * *}$ & $15.5 \pm 6.3^{* *}$ & $8.9 \pm 7.7$ \\
\hline & \multirow[t]{2}{*}{ IL-1 $\beta$} & $0.85 \pm 0.18$ & $17.2 \pm 2.1^{* * * \#}$ & $15.3 \pm 2.0^{* * * \#}$ & $15.1 \pm 1.5^{* * *}$ & $8.5 \pm 1.8^{* * *}$ \\
\hline & & & $5.9 \pm 2.2^{* *}$ & $6.3 \pm 1.8^{* *}$ & $8.8 \pm 3.2^{* *}$ & $4.5 \pm 2.6$ \\
\hline Group 4 & RANTES & $0.14 \pm 0.04$ & $1.38 \pm 0.2^{\#}$ & $1.39 \pm 0.2$ & $2.63 \pm 0.8^{*}$ & $4.37 \pm 1.4^{* \#}$ \\
\hline & & & $0.60 \pm 0.1$ & $0.93 \pm 0.2$ & $3.91 \pm 1.3$ & $1.12 \pm 0.3$ \\
\hline & IFN $\gamma$ & $0.79 \pm 0.22$ & $0.90 \pm 0.6$ & $4.04 \pm 0.6^{* *}$ & $3.34 \pm 0.7^{*}$ & $1.39 \pm 0.5$ \\
\hline & & & $1.77 \pm 0.2$ & $2.49 \pm 0.3^{*}$ & $2.21 \pm 0.7$ & $1.26 \pm 0.6$ \\
\hline & Leptin & $2.48 \pm 0.67$ & $1.28 \pm 0.4$ & $0.95 \pm 0.3$ & $1.35 \pm 0.2$ & $2.24 \pm 0.7$ \\
\hline & & & $0.62 \pm 0.1$ & $1.27 \pm 0.2$ & $2.28 \pm 0.4^{*}$ & $1.73 \pm 0.3$ \\
\hline & Fractalkine & $0.58 \pm 0.03$ & $1.22 \pm 0.1$ & $1.27 \pm 0.2$ & $1.25 \pm 0.1$ & $1.41 \pm 0.2$ \\
\hline & & & $1.34 \pm 0.1^{* *}$ & $1.52 \pm 0.1^{* *}$ & $1.44 \pm 0.1^{* *}$ & $1.29 \pm 0.1^{*}$ \\
\hline & VEGF & $1.32 \pm 0.03$ & $0.79 \pm 0.2$ & $1.23 \pm 0.2$ & $1.09 \pm 0.1$ & $0.72 \pm 0.0^{* *}$ \\
\hline & & & $0.78 \pm 0.1^{*}$ & $0.95 \pm 0.0$ & $0.88 \pm 0.1$ & $0.80 \pm 0.1$ \\
\hline & $\mathbb{P}-10$ & $0.72 \pm 0.16$ & $5.69 \pm 0.9^{* * *}$ & $7.14 \pm 0.7^{* * *}$ & $6.60 \pm 0.7^{* * *}$ & $4.14 \pm 1.0^{* *}$ \\
\hline & & & $4.78 \pm 1.3^{* *}$ & $6.82 \pm 0.9^{* * *}$ & $4.16 \pm 0.8^{* *}$ & $2.13 \pm 0.3^{*}$ \\
\hline & $\operatorname{TNF} \alpha$ & $2.03 \pm 0.44$ & $0.59 \pm 0.1$ & $0.51 \pm 0.1$ & $0.44 \pm 0.1^{* \#}$ & $0.50 \pm 0.1$ \\
\hline & & & $0.91 \pm 0.2$ & $1.00 \pm 0.2$ & $0.70 \pm 0.1$ & $0.79 \pm 0.2$ \\
\hline
\end{tabular}

${ }^{a} \mathrm{~N}=5$ normal male rats; 4 male rats per group in all other groups and time points. Both $\mathrm{L} 4$ and $\mathrm{L} 5 \mathrm{DRG}$ were inflamed and combined into a single sample. Absolute values of cytokine concentration shown for normal DRG are in the lysate (see Materials and Methods), depend on method of protein normalization, number of DRG per sample, and sample volume, and hence are not directly comparable with our previous study (Xie et al. 2006).

${ }^{b}$ Average of concentrations in the DRG samples ( $\mathrm{pg} / \mathrm{ml}$ ) divided by $\mu \mathrm{g}$ protein.

Fold change was determined by normalizing values to the average value in normal DRG. Top value in each row, inflamed DRG plus sham mSYMPX; lower value, inflamed DRG plus mSYMPX. mSYMPX or sham mSYMPX was performed $7 \mathrm{~d}$ before DRG inflammation.

${ }^{*} p<0.05 ;{ }^{* *} p<0.01 ;{ }^{* * *} p<0.001$; significantly different from normal (ratio $t$ test).

$\# p<0.05 ; \# p<0.01 ; \# p<0.001$; significant difference between mSYMPX and sham SYMPX groups (ratio $t$ test).

number of action potentials that could be evoked by suprathreshold current stimuli was increased by LID and normalized by mSYMPX, whereas the increased percentage of cells that could be stimulated to produce subthreshold oscillations was partially normalized.

In these experiments, the DRGs from animals receiving the prior mSYMPX followed by DRG inflammation surgery were compared with DRGs from animals receiving either DRG inflammation or a similar surgical exposure of the DRG but without inflammation; however, the latter two groups did not include an additional prior sham mSYMPX procedure. We have previously found that such surgeries (exposing the DRG in the absence of DRG inflammation) do not themselves alter the electrophysiological properties of the sensory neurons (Xie et al., 2015, 2016), and hence we deemed it unlikely that the effects of mSYMPX would have been due simply to the presence of a second surgery per se, rather than to the MSYMPX. If anything, a second surgery alone might be expected to cause inflammation and increase, rather than decrease, neuronal excitability. However, the lack of sham mSYMPX control animals with 2 surgeries is a limitation of the data.

Changes in $\mathrm{A} \delta$ and $\mathrm{C}$ cells are relatively minor in this model (Xie et al., 2013) and were not affected by mSYMPX (data not shown).

mSYMPX decreased markers of DRG inflammation

Although much research about the role of sympathetic fibers in the DRG and pain has focused on the role of sympathetic sprouting around neuronal cell bodies, the LID model induces sprouting that is more modest than that observed in the spinal nerve ligation model and is still increasing on POD 7 (Xie et al., 2006). Because behavioral effects of mSYMPX were marked as early as POD 1, we hypothesized based on the literature that another mechanism that might plausibly be in effect even at the earliest 

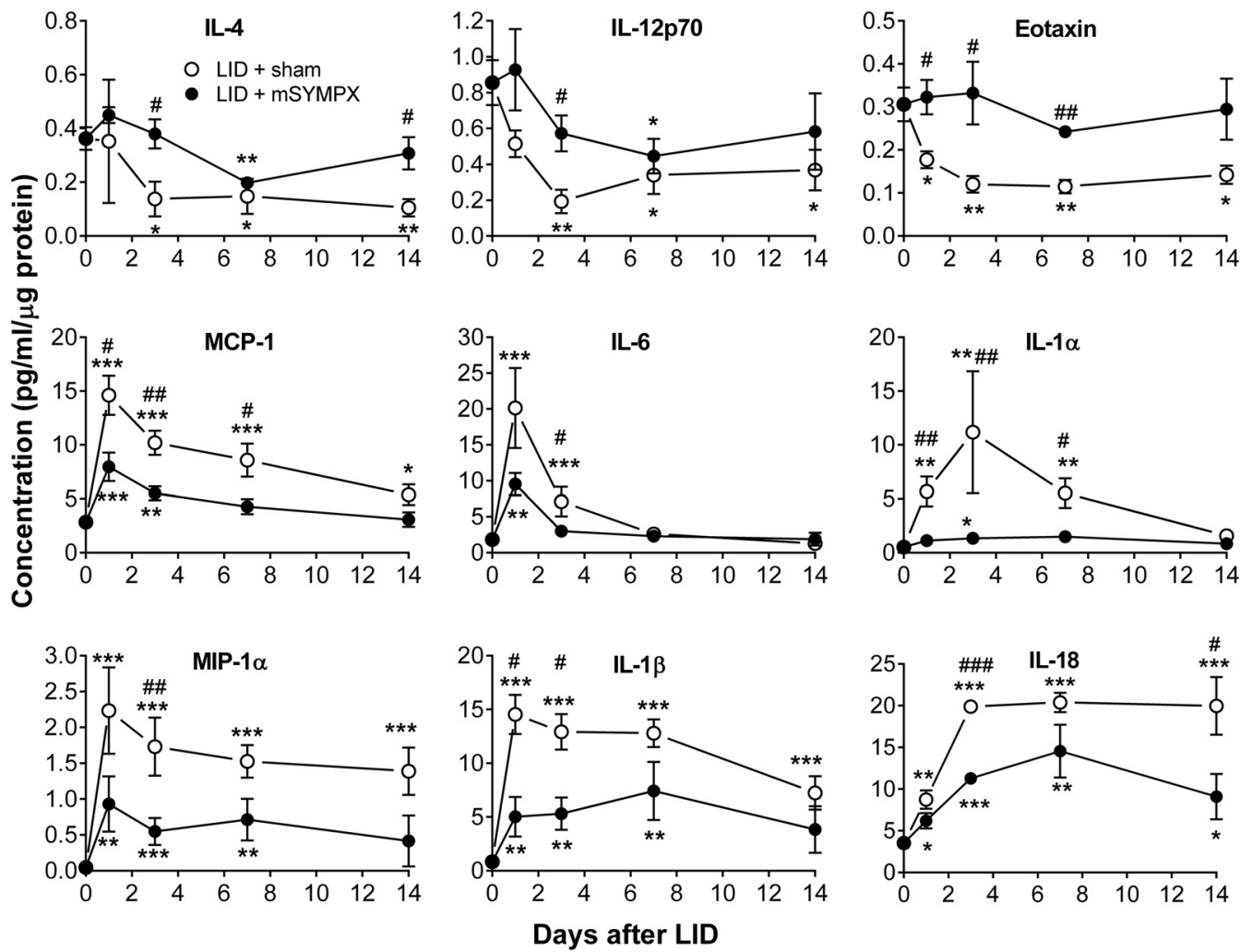

Figure 6. Examples of cytokine profiles after local DRG inflammation with mSYMPX or sham mSYMPX performed $7 \mathrm{~d}$ before DRG inflammation (POD 0). The concentrations in the DRG samples $(\mathrm{pg} / \mathrm{ml})$ were divided by the $\mu \mathrm{g}$ protein present in the sample. Normal DRG values (samples taken from normal animals with no surgical procedures) are plotted on day 0 . Top, Examples of cytokines from Group 1 that were decreased by LID and partly normalized by mSYMPX. Middle, Examples of pro-inflammatory cytokines from Group 2 that were initially increased by LID and partially normalized by mSYMPX. Bottom, Examples of pro-inflammatory cytokines from Group 3, showing a more sustained increase after LID and partially normalized by mSYMPX. Significant fold change compared with normal DRG at the indicated time point: ${ }^{*} p<0.05 ;{ }^{* *} p<0.01$; ${ }^{* * *} p<0.001$. Significant difference in fold change between sham mSYMPX and mSYMPX groups on the indicated days (ratio $t$ test): ${ }^{\#} p<0.05 ;{ }^{\# \#} p<0.01 ;{ }^{\# \#} p<0.001 . N=5$ normal samples and 4 samples per group in all other groups. See also Table 2.

time points, namely, reduction of inflammation. Evidence for suppression of inflammation in the DRG after mSYMPX was obtained by staining DRG sections for the macrophage marker Iba-1. As shown in Figure 5, DRG inflammation increased the density of macrophage staining in the cellular areas of the DRG on POD 4 (consistent with our previous study using a different marker) (Xie et al., 2006), and this increase was blocked by performing mSYMPX before inflaming the DRG. Macrophages have recently been shown to play key functional roles in the CFA model and the paw incision model in mice, more so than neutrophils or T cells (Ghasemlou et al., 2015).

We have previously shown that the LID model leads to upregulation of several pro-inflammatory cytokines and downregulation of some anti-inflammatory cytokines at the protein level (Xie et al., 2006). Here, we used a multiplex method to examine the effect of mSYMPX on this cytokine profile. Protein samples were isolated from control DRGs and from DRGs with either prior mSYMPX or prior sham mSYMPX followed $7 \mathrm{~d}$ later by local DRG inflammation. Samples were obtained 1, 3, 7, and $14 \mathrm{~d}$ after DRG inflammation. A total of 21 rat cytokines was measured. Full names, systemic names, and alternative names of the cytokines examined are given in Table 1. The results from 19 cytokines are shown in Table 2, and examples are shown in Figure 6. Generally, the cytokine profiles fell into 4 groups (though not every difference was significant at every time point). Group 1 consisted of 4 cytokines (Table 2; examples in Fig. 6, top) that declined after induction of DRG inflammation but were maintained at levels closer to those present in the normal DRG in animals receiving mSYMPX. Interestingly, 3 of the 4 cytokines are either Th2 products (IL-2, IL-4) or directly induced by products of Th2 cells (eotaxin). IL-2, IL-12p70, and IL-4 showed a similar pattern after LID in our previous study, although not always reaching significance; eotaxin was not measured in that study. Group 2 consisted of 5 cytokines (Table 2; examples in Fig. 6 , middle) that showed an increase after LID with an early peak, and these increases were mitigated by prior mSYMPX. The 3 cytokines in Group 3 (Table 2; Fig. 6, bottom) had a profile that was similar to Group 2, except that the increases in proinflammatory cytokines were more sustained. The majority of the cytokines in Groups 2 and 3 are involved in Type 1 inflammation and are either directly chemotactic (MCP-1, MIP-2, GRO/KC, MIP-1 $\alpha$ ), or associated with enhanced Th1 or Th17 cell activity/ differentiation (IL-18, IL-1 $\beta$, IL-6). As shown in Table 2, some of the anti-inflammatory effects of MSYMPX on the cytokine profile were significant even on POD 1, the earliest time point studied. Several of the cytokines in Groups 2 and 3 showed a similar pattern after LID in our previous study, though not always showing significant differences from sham LID animals on POD 1 or POD 3; that study used a more surgically invasive procedure and corresponding sham for the LID model (see Materials and Methods). The final group (Group 4; Table 2) consisted of 7 cytokines that were little affected by mSYMPX; some (e.g., IFN $\gamma$, IP-10) showed increases with DRG inflammation, whereas others had a relatively flat time course. Two cytokines were measured but not presented in Table 2. EGF had very low absolute concentrations in all samples and large SEM. The anti-inflammatory cytokine 


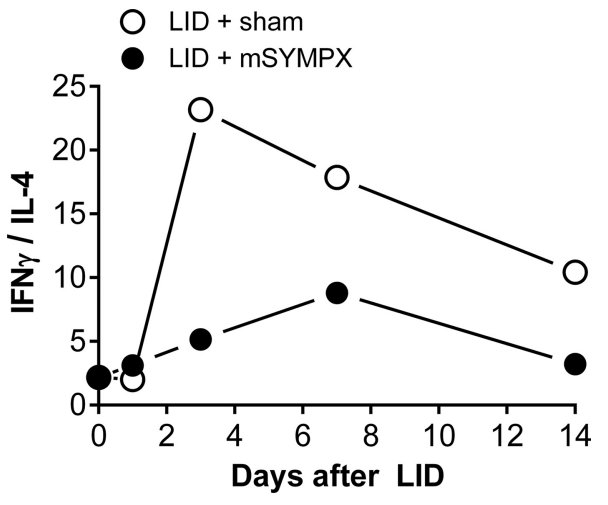

Figure 7. Effect of prior mSYMPX on ratio of IFN $\gamma$ to IL-4 in DRG samples from locally inflamed DRG. Higher ratios indicate a greater Th1/Th17 skewed Type 1 inflammatory response. Lower ratios indicate a more Th2 skewed response. The plotted values are the ratios of IFN $\gamma$ protein to IL-4 protein. Ratios were derived from the data in Table 2.

IL-10 also had very low absolute concentrations; the profile was similar to Group 1, but changes from normal did not reach significance. Overall, the picture painted by these data are of increased Type 1 pro-inflammatory levels (because many of the upregulated cytokines are derived from or involved in regulating e.g., Type 1 macrophages and Th cells) and decreased Type 2 cytokine levels in the inflamed DRG (as previously demonstrated), along with partial mitigation of these changes by mSYMPX.

mSYMPX appears to limit the intensity of the induced Type 1 inflammatory responses, maintaining the balance in favor of Type 2 immunity. Consistent with this interpretation, the ratio of IFN $\gamma$ to IL-4 was markedly increased by LID, and this was partially mitigated by prior mSYMPX (Fig. 7). Higher values of this ratio indicate a more Type 1 inflammation-skewed response, and lower values a more Type 2 inflammation skewed response (see, e.g., Gabrielsson et al., 1997; Scola et al., 2002). Type 1 or classical inflammation involves tissue destruction, nitric oxide, reactive oxygen species, cytokines, and M1 polarized macrophages and Th1 T cells, whereas Type 2 inflammation, which includes Th2 cells, M2 macrophages, eosinophils, and cytokines, sometimes referred to as anti-inflammatory (because they oppose Type 1 inflammation), is involved with tissue remodeling, wound healing, and clearance of multicellular parasites, but also with deleterious events, such as allergy and fibrosis (Rickard and Young, 2009; Allen and Sutherland, 2014).

\section{mSYMPX reduced pain and inflammation induced by CFA paw injection}

The mSYMPX procedure will also remove sympathetic innervation in most of the hindpaw. We tested whether the procedure affected a pain model in which inflammation is initiated peripherally, in the affected hindpaw, rather than at the lumbar DRG. As shown in Figure 8, mSYMPX 14 d before the CFA injection markedly reduced the mechanical pain behaviors induced by injection of a low dose of CFA into the paw. The effect of mSYMPX on mechanical allodynia (Fig. 8B) was large, and the difference between the two groups was significant on all days tested (two-way repeated-measures ANOVA). One-way ANOVA comparing baseline with other time points within the mSYMPX + CFA group showed that responses did not differ significantly from baseline on any day tested, whereas the same type of analysis applied to the sham mSYMPX group showed that responses differed from baseline on all days tested. von Frey responses (Fig. $8 A$ ) were also significantly different between the two groups at all

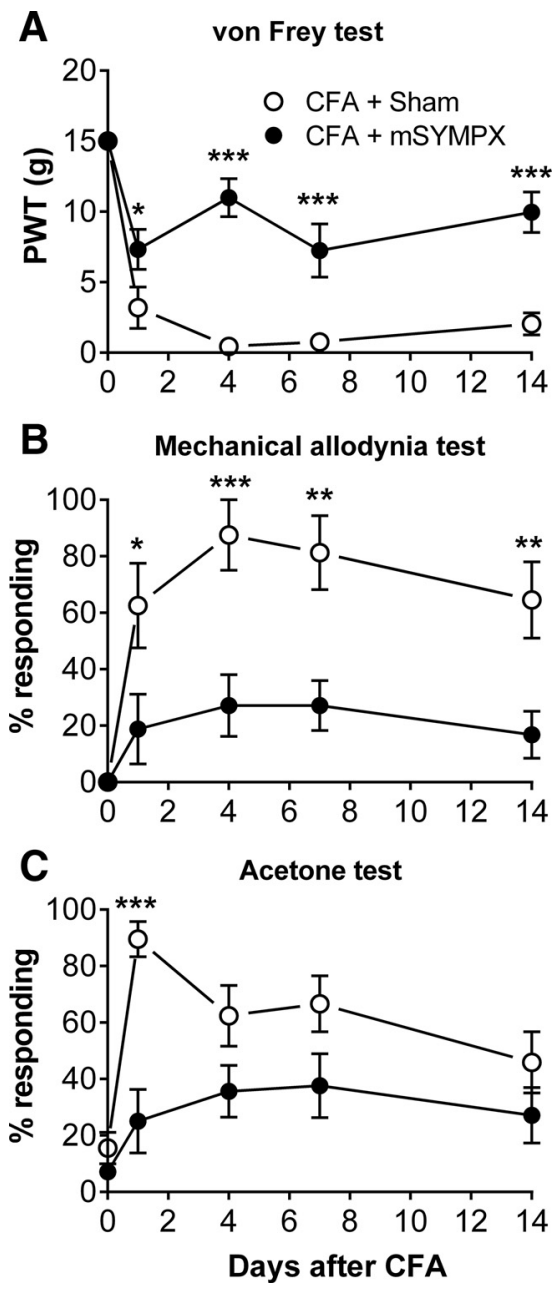

Figure 8. Effects of mSYMPX on the CFA model of peripheral inflammation. CFA paw injection was performed on POD 0, $14 \mathrm{~d}$ after mSYMPX or sham mSYMPX surgery. As in prior experiments (Fig. 2), this did not affect baseline responses (average baseline plotted on POD 0 ). CFA-induced changes in von Frey responses $(\boldsymbol{A})$ and mechanical allodynia test $(\boldsymbol{B})$ were significantly reduced in $\mathrm{mSYMPX}$ animals on all days tested. Cold responses $(\boldsymbol{C})$ differed between the two groups on POD 1 only. ${ }^{*} p<0.05 ;{ }^{* *} p<0.01 ;{ }^{* * *} p<0.001$; significant difference between groups at indicated time points (two-way repeated-measures ANOVA with Bonferroni post hoc test). $N=8$ male animals per group. Experimenter was blinded to the $\mathrm{mSYMPX/sham}$ status.

time points tested (two-way repeated-measures ANOVA). However, the effect of mSYMPX on the von Frey responses was not complete; one-way ANOVA comparing baseline to other time points within the MSYMPX + CFA group showed that responses still differed significantly from baseline on all days, except POD 4. For cold responses, the differences between the mSYMPX and sham mSYMPX groups were significant only on POD 1. However, one-way ANOVA comparing baseline cold responses with other time points within the MSYMPX + CFA group showed that cold responses were not significantly different from baseline at any time point.

The swelling induced by CFA inflammation was also significantly reduced by mSYMPX (Fig. 9D), from POD 1 through POD 14 (last time point measured). The reduction in inflammation indicated by the paw swelling data was qualitatively confirmed with $\mathrm{H} \& \mathrm{E}$ staining on POD 7 (Fig. $9 A-C$ ) as indicated by less thickening of the skin, relatively preserved normal skin structure, less edema, less inflammatory cell infiltration, and a more intact corneum in the mSYMPX group. Additional evidence that the 

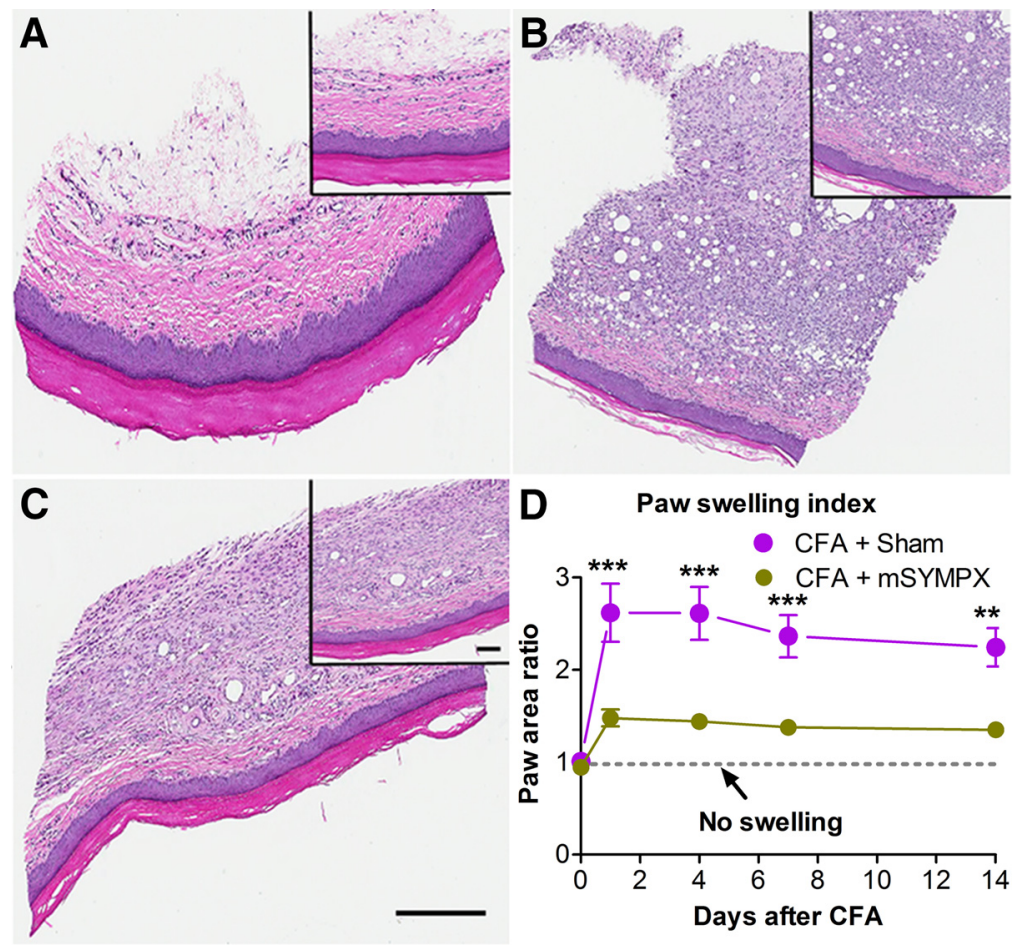

Figure 9. H\&E staining shows MSYMPX reduced paw inflammation in the CFA model. Samples of cross sections of the paw skin taken near the injection site were processed with the H\&E method. $A$, Normal paw skin from animal with no CFA injection. $\boldsymbol{B}$, Seven days after (FA injection with sham mSYMPX (14 d before (FA injection). C, Seven days after (FA injection with mSYMPX (14 d before CFA injection). There is greater edema, swelling, and immune cell infiltration in $\boldsymbol{B}$ compared with $C$. Scale bars, $200 \mu \mathrm{m}$; low-power inset, $400 \mu \mathrm{m}$. Similar results were obtained in 4 male animals per group. $\boldsymbol{D}$, The paw swelling index (paw width $\times$ paw height, normalized to the contralateral paw) was significantly lower in the mSYMPX group on all days tested. Dotted line indicates index of 1 (no swelling). ${ }^{* *} p<0.01 ;{ }^{* * *} p<0.001$, significant difference between groups at indicated time points (two-way repeated-measures ANOVA with Bonferroni post hoc test). $N=8$ male animals per group (same animals as Fig. 8).

mSYMPX procedure reduced paw inflammation was obtained by staining skin sections with the macrophage marker Iba-1. As shown in Figure 10, macrophage density increased in the CFA model on POD4, and this was reduced to normal levels by prior mSYMPX.

\section{Discussion}

Sympathetic fibers are associated primarily with blood vessels around the normal DRG, and are also distributed over its surface (Xie et al., 2010), but do not directly innervate sensory neurons. Because we observed marked reduction of pain behaviors by cutting the gray rami near the lumbar DRG that was significant as soon as $1 \mathrm{~d}$ after DRG inflammation, one likely explanation of our findings is that loss of sympathetic fibers in the DRG region reduced local inflammation, as indicated by microscopy and cytokine data. We also observed reduction of paw inflammation in the CFA model after mSYMPX. Mechanisms by which local sympathectomy might directly reduce inflammation include direct effects of sympathetic transmitters on immune cells (see Introduction), effects on endothelial cells to modify immune cell extravasation (Mousa et al., 2010), and alterations in local blood flow (though the latter may be very short-lived) (Yanagiya et al., 1999; Onda et al., 2004; Sekiguchi et al., 2008). We cannot rule out contributions from additional nonlocal effects of our mSYMPX procedure, such as changes in nonaxotomized sympathetic neurons secondary to DRG inflammation or axotomy of neighboring cells, or effects of sympathetic denervation of the draining lymph nodes or some bone marrow sites. However, in a recent study examining inflammation in the lumbar DRG induced by remote sciatic nerve injury, isolated sympathetic denervation of only the draining lymph node had no effect on macrophages and increased T-cell infiltration of the DRG only at later time points (McLachlan and $\mathrm{Hu}, 2014)$. Despite the very different models used (local DRG inflammation vs sciatic nerve transection), this study, like ours, reported decreased DRG inflammation following a relatively localized sympathectomy (removal of L3/L4 sympathetic ganglia).

Our preliminary observation that mSYMPX was also effective in the chronic DRG compression model suggests that the findings are not restricted to the particular type of immune stimulus used in the LID model. Surgical sympathectomy reduced pain in other preclinical back pain models (Murata et al., 2006a; Iwase et al., 2012; Ogon et al., 2015). The Iwase et al. (2012) study also demonstrated reduction of sensory neuron hyperexcitability by sympathectomy, as in our study.

The observed changes in cytokine profiles confirm and extend our previous findings in the LID model (Xie et al., 2006), and demonstrate that mSYMPX mitigates many of the changes in cytokine production observed in that model. Moreover, we report for the first time altered expression of MIP-1 $\alpha$, MIP-2 (both upregulated by LID, mitigated by mSYMPX), eotaxin (downregulated by LID, normalized by mSYMPX), and IP-10 (upregulated by LID but little affected by mSYMPX). Although the mechanisms whereby these cytokines may drive development of pain remain unclear, several of the pro-inflammatory cytokines elevated by LID and reduced by MSYMPX have been previously shown to have direct excitatory effects on sensory neurons, including IL$1 \alpha$, IL-1 $\beta$, MCP-1, IL-6, MIP-1 $\alpha$, and MIP-2 (Miller et al., 2009; Austin and Moalem-Taylor, 2010; Dawes and McMahon, 2013). Although many studies have implicated TNF- $\alpha$ in pain, we found it to be minimally affected or even downregulated by LID, in both this and our prior study. TNF- $\alpha$ is known to upregulate several of the cytokines upregulated in our data, so it might have been briefly upregulated at earlier time points than we studied. It has been suggested in some preclinical studies that TNF- $\alpha$ is important only during the early stages (Goupille et al., 2007; Sasaki et al., 2007; Andrade et al., 2011).

Taken as a whole, the cytokine profiling data are consistent with Type 1 inflammation occurring after LID, which is plausible given that the model involves application of zymosan (a TLR2 agonist), in the context of IFA (a powerful immune-activating adjuvant). We propose that the Type 1 local DRG inflammation is associated with pain and is reduced by MSYMPX, as indicated by the cytokine profile and by the IFN $\gamma$ :IL-4 ratio (Gabrielsson et al., 2001; Cai et al., 2016) (Fig. 7). Our cytokine data (including basal levels of IL-4 and eotaxin that decrease in LID) also suggest a protective Th2/M2 bias in normal DRG, consistent with observations in CNS (Kobayashi et al., 2002; Foster et al., 2011; Walsh 
et al., 2015) and other tissues (Italiani and Boraschi, 2015). Type 1 immune responses have been implicated in damage to nervous tissue (Wolf et al., 2002; Reynolds et al., 2010; Tanabe and Yamashita, 2014; Walsh et al., 2015) and increased pain in several models (Moalem et al., 2004; Draleau et al., 2014; Liu et al., 2014). It should be noted that, in the DRG, some of the cytokines we measured may have sources and targets distinct from, or in addition to, their established immune cell roles (see, e.g., Liu et al., 2014 on the key role of immune molecules expressed by neurons in regulating the immune response). The effects of DRG inflammation and localized sympathectomy on the types and polarization of immune cells present remain to be elucidated, although we did observe reduced macrophage staining after mSYMPX.

The effects of mSYMPX on mechanical pain behaviors were dramatic and much larger than we initially expected. The von Frey and mechanical responses were reduced by mSYMPX to baseline levels on most of the tested days in both the LID and DRG compression models. Both models involve inflammation at the level of the DRG in the absence of overt axon transection. Both are intended to model aspects of low back pain. In this regard, it of interest that a recent study showed some human patients with radicular pain also exhibit tactile and cold allodynia in the limbs, sometimes extending all the way to the foot, when examined with quantitative sensory testing, including von Frey testing (Defrin et al., 2014). We previously observed similarly large behavioral effects of cutting the gray rami to L4 and L5 DRG in the L5 spinal nerve ligation model, in which there is axon transection but also a relatively high degree of local DRG inflammation due to the proximity of the axon injury (Xie et al., 2010). In contrast, global chemical sympathectomy had only minor, delayed effects in the spared nerve injury model, in which the injury is more remote from the DRG (Pertin et al., 2007). It would be of interest to test the effects of a more local sympathectomy in this model.

The anti-inflammatory effects of MSYMPX we observed in the CFA model of peripheral inflammation are consistent with a previous study showing that chemical or surgical sympathectomy 3-7 d prior reduced mechanical pain and paw swelling induced by bee venom injection into the paw (Chen et al., 2010); however, these findings differ dramatically from a study showing almost no effect of neonatal chemical sympathectomy on pain behaviors in the CFA model (Woolf et al., 1996). Perhaps compensatory mechanisms induced by neonatal global sympathectomy account for these discrepancies.

The literature is very contradictory regarding effects of surgical sympathectomy on preclinical pain models (Pertin et al., 2007). Even for the same model (e.g., spinal nerve ligation), findings in different laboratories range from no effect of sympathectomy (e.g., Ringkamp et al., 1999) to almost complete block of pain behaviors (e.g., Kim et al., 1993; Choi et al., 1994). Although our data cannot directly explain these discrepancies, our study suggests that differing degrees of inflammation might result in differing susceptibility to sympathetic influence. The lumbar surgical sympathectomy performed in many studies is difficult and more invasive than most pain model surgeries, perhaps providing more room for technical differences to influence the outcome. Notably, one laboratory reported that the sympathetic effect in the spinal nerve ligation model was altered by making a minor modification to the model or even by the switch to pathogen-free rats (Xie et al., 2001). The mSYMPX we describe here is technically simpler and less invasive; it will be of interest to determine whether it provides less variable results.

We found that MSYMPX was still effective when performed $14 \mathrm{~d}$ after DRG inflammation, a time at which pain behaviors are well established. Observed decreases in 4 anti-inflammatory cytokines were sustained through POD 14; and of these, IL-4 was partially normalized by prior mSYMPX. Three pro-inflammatory cytokines showed sustained increases through POD 14; and of these, IL-18 and MIP- $1 \alpha$ were partially normalized by prior mSYMPX. These cytokines with sustained changes that are affected by mSYMPX and, hence, that correlate with pain behaviors, may be interesting candidates to investigate to understand pain maintenance. It will be of interest to determine whether MSYMPX is effective at even later times because some studies suggest that at later times in the course of some human diseases or preclinical pain models the role of the SNS switches to become anti-inflammatory (AbuRahma et al., 1994; Aley et al., 1996; Straub et al., 2006; Koopman et al., 2011; Amr and Makharita, 2014; Schaible and Straub, 2014). In contrast, a recent clinical study (Agarwal-Kozlowski et al., 2011) showed dramatic reductions in chronic pain using a catheter approach to provide longer lasting sympathetic blockade than is achieved by injection, in 293 
patients with intractable pain (including 69 with CRPS). Because pain relief often required more than a week of blockade, the authors noted that most patients would have been traditionally classified as having sympathetically independent pain. There is a need for further preclinical research in this area that will complement the expanding clinical interest. In particular, our findings suggest that cutting the sympathetic innervation of the lumbar spinal outflow might give profound reductions in pain behaviors. It would be interesting to determine whether some localized clinical interventions targeting the sensory neurons (e.g., epidural steroid injection or radiofrequency lesion) are acting in part through local effects on sympathetic nerves. Our findings suggest that targeting the lumbar gray rami might provide a method to reduce pain without damaging the sensory or motor supply.

\section{References}

Abramov R (2014) Lumbar sympathetic treatment in the management of lower limb pain. Curr Pain Headache Rep 18:403. CrossRef Medline

AbuRahma AF, Robinson PA, Powell M, Bastug D, Boland JP (1994) Sympathectomy for reflex sympathetic dystrophy: factors affecting outcome. Ann Vasc Surg 8:372-379. CrossRef Medline

Agarwal-Kozlowski K, Lorke DE, Habermann CR, Schulte am Esch J, Beck H (2011) Interventional management of intractable sympathetically mediated pain by computed tomography-guided catheter implantation for block and neuroablation of the thoracic sympathetic chain: technical approach and review of 322 procedures. Anaesthesia 66:699-708. CrossRef Medline

Aley KO, Kinnman E, Levine JD (1996) Delayed sympathectomy after a prolonged hyperalgesia results in a subsequent enhanced acute hyperalgesic response. Neuroscience 71:1083-1090. CrossRef Medline

Allen JE, Sutherland TE (2014) Host protective roles of Type 2 immunity: parasite killing and tissue repair, flip sides of the same coin. Semin Immunol 26:329-340. CrossRef Medline

Almarestani L, Longo G, Ribeiro-da-Silva A (2008) Autonomic fiber sprouting in the skin in chronic inflammation. Mol Pain 4:56. CrossRef Medline

Almarestani L, Fitzcharles MA, Bennett GJ, Ribeiro-da-Silva A (2011) Imaging studies in Freund's complete adjuvant model of regional polyarthritis, a model suitable for the study of pain mechanisms, in the rat. Arthritis Rheum 63:1573-1581. CrossRef Medline

Amaya F, Samad TA, Barrett L, Broom DC, Woolf CJ (2009) Periganglionic inflammation elicits a distally radiating pain hypersensitivity by promoting COX-2 induction in the dorsal root ganglion. Pain 142:59-67. CrossRef Medline

Amr YM, Makharita MY (2014) Neurolytic sympathectomy in the management of cancer pain-time effect: a prospective, randomized multicenter study. J Pain Symptom Manage 48:944-956. CrossRef Medline

Andrade P, Visser-Vandewalle V, Hoffmann C, Steinbusch HW, Daemen MA, Hoogland G (2011) Role of TNF-alpha during central sensitization in preclinical studies. Neurol Sci 32:757-771. CrossRef Medline

Austin PJ, Moalem-Taylor G (2010) The neuro-immune balance in neuropathic pain: involvement of inflammatory immune cells, immune-like glial cells and cytokines. J Neuroimmunol 229:26-50. CrossRef Medline

Baron R, Jänig W, Kollmann W (1988) Sympathetic and afferent somata projecting in hindlimb nerves and the anatomical organization of the lumbar sympathetic nervous system of the rat. J Comp Neurol 275: 460-468. CrossRef Medline

Bellinger DL, Millar BA, Perez S, Carter J, Wood C, ThyagaRajan S, Molinaro C, Lubahn C, Lorton D (2008) Sympathetic modulation of immunity: relevance to disease. Cell Immunol 252:27-56. CrossRef Medline

Benarroch EE (2009) Autonomic-mediated immunomodulation and potential clinical relevance. Neurology 73:236-242. CrossRef Medline

Borchers AT, Gershwin ME (2014) Complex regional pain syndrome: a comprehensive and critical review. Autoimmun Rev 13:242-265. CrossRef Medline

Cai M, Zhou T, Wang X, Shang M, Zhang Y, Luo M, Xu C, Yuan W (2016) DC-SIGN expression on podocytes and its role in inflammatory immune response of lupus nephritis. Clin Exp Immunol 183:317-325. CrossRef Medline

Chaplan SR, Bach FW, Pogrel JW, Chung JM, Yaksh TL (1994) Quantitative assessment of tactile allodynia in the rat paw. J Neurosci Methods 53:5563. CrossRef Medline

Chen HS, Qu F, He X, Wang Y, Wen WW (2010) Chemical or surgical sympathectomy prevents mechanical hyperalgesia induced by intraplantar injection of bee venom in rats. Brain Res 1353:86-93. CrossRef Medline

Choi Y, Yoon YW, Na HS, Kim SH, Chung JM (1994) Behavioral signs of ongoing pain and cold allodynia in a rat model of neuropathic pain. Pain 59:369-376. CrossRef Medline

Chung K, Kim HJ, Na HS, Park MJ, Chung JM (1993) Abnormalities of sympathetic innervation in the area of an injured peripheral nerve in a rat model of neuropathic pain. Neurosci Lett 162:85-88. CrossRef Medline

Cline JM, Maronpot RR (1985) Variations in the histologic distribution of rat bone marrow cells with respect to age and anatomic site. Toxicol Pathol 13:349-355. CrossRef Medline

Dawes JM, McMahon SB (2013) Chemokines as peripheral pain mediators. Neurosci Lett 557:1-8. CrossRef Medline

de Souza Grava AL, Ferrari LF, Defino HL (2012) Cytokine inhibition and time-related influence of inflammatory stimuli on the hyperalgesia induced by the nucleus pulposus. Eur Spine J 21:537-545. CrossRef Medline

Defrin R, Devor M, Brill S (2014) Tactile allodynia in patients with lumbar radicular pain (sciatica). Pain 155:2551-2559. CrossRef Medline

Donaldson LF, Seckl JR, McQueen DS (1993) A discrete adjuvant-induced monoarthritis in the rat: effects of adjuvant dose. J Neurosci Methods 49:5-10. CrossRef Medline

Draleau K, Maddula S, Slaiby A, Nutile-McMenemy N, De Leo J, Cao L (2014) Phenotypic identification of spinal cord-infiltrating CD4 T lymphocytes in a murine model of neuropathic pain. J Pain Relief [Suppl 3]:003.

Drummond PD (2013) Sensory-autonomic interactions in health and disease. Handb Clin Neurol 117:309-319. CrossRef Medline

duPont NC, Wang K, Wadhwa PD, Culhane JF, Nelson EL (2005) Validation and comparison of luminex multiplex cytokine analysis kits with ELISA: determinations of a panel of nine cytokines in clinical sample culture supernatants. J Reprod Immunol 66:175-191. CrossRef Medline

Dworkin RH, O'Connor AB, Kent J, Mackey SC, Raja SN, Stacey BR, Levy RM, Backonja M, Baron R, Harke H, Loeser JD, Treede RD, Turk DC, Wells CD, Wells CD (2013) Interventional management of neuropathic pain: NeuPSIG recommendations. Pain 154:2249-2261. CrossRef Medline

Elenkov IJ (2008) Neurohormonal-cytokine interactions: implications for inflammation, common human diseases and well-being. Neurochem Int 52:40-51. CrossRef Medline

Foster EL, Simpson EL, Fredrikson LJ, Lee JJ, Lee NA, Fryer AD, Jacoby DB (2011) Eosinophils increase neuron branching in human and murine skin and in vitro. PLoS One 6:e22029. CrossRef Medline

Gabrielsson S, Paulie S, Roquet A, Ihre E, Lagging E, van Hage-Hamsten M, Härfast B, Troye-Blomberg M (1997) Increased allergen-specific Th2 responses in vitro in atopic subjects receiving subclinical allergen challenge. Allergy 52:860-865. CrossRef Medline

Gabrielsson S, Söderlund A, Nilsson C, Lilja G, Nordlund M, TroyeBlomberg M (2001) Influence of atopic heredity on IL-4-, IL-12- and IFN-gamma-producing cells in in vitro activated cord blood mononuclear cells. Clin Exp Immunol 126:390-396. CrossRef Medline

Ghasemlou N, Chiu IM, Julien JP, Woolf CJ (2015) CD11b ${ }^{+}$Ly6G $^{-}$myeloid cells mediate mechanical inflammatory pain hypersensitivity. Proc Natl Acad Sci U S A 112:E6808-E6817. CrossRef Medline

Goupille P, Mulleman D, Paintaud G, Watier H, Valat JP (2007) Can sciatica induced by disc herniation be treated with tumor necrosis factor alpha blockade? Arthritis Rheum 56:3887-3895. CrossRef Medline

Harden RN, Oaklander AL, Burton AW, Perez RS, Richardson K, Swan M, Barthel J, Costa B, Graciosa JR, Bruehl S (2013) Complex regional pain syndrome: practical diagnostic and treatment guidelines. Pain Med 14: 180-229. CrossRef Medline

H“arle P, Möbius D, Carr DJ, Schölmerich J, Straub RH (2005) An opposing time-dependent immune-modulating effect of the sympathetic nervous system conferred by altering the cytokine profile in the local lymph nodes and spleen of mice with type II collagen-induced arthritis. Arthritis Rheum 52: 1305-1313. CrossRef Medline

Haskó G (2001) Receptor-mediated interaction between the sympathetic nervous system and immune system in inflammation. Neurochem Res 26:1039-1044. CrossRef Medline 
Haug SR, Heyeraas KJ (2006) Modulation of dental inflammation by the sympathetic nervous system. J Dent Res 85:488-495. CrossRef Medline

Huang ZJ, Hsu E, Li HC, Rosner AL, Rupert RL, Song XJ (2011) Topical application of compound Ibuprofen suppresses pain by inhibiting sensory neuron hyperexcitability and neuroinflammation in a rat model of intervertebral foramen inflammation. J Pain 12:141-152. CrossRef Medline

Hu P, McLachlan EM (2002) Macrophage and lymphocyte invasion of dorsal root ganglia after peripheral nerve lesions in the rat. Neuroscience 112:23-38. CrossRef Medline

Italiani P, Boraschi D (2015) New insights Into tissue macrophages: from their origin to the development of memory. Immune Netw 15:167-176. CrossRef Medline

Iwase T, Takebayashi T, Tanimoto K, Terashima Y, Miyakawa T, Kobayashi T, Tohse N, Yamashita T (2012) Sympathectomy attenuates excitability of dorsal root ganglion neurons and pain behaviour in a lumbar radiculopathy model. Bone Joint Res 1:198-204. CrossRef Medline

Kawakami M, Tamaki T, Weinstein JN, Hashizume H, Nishi H, Meller ST (1996) Pathomechanism of pain-related behavior produced by allografts of intervertebral disc in the rat. Spine 21:2101-2107. CrossRef Medline

Kim SH, Na HS, Sheen K, Chung JM (1993) Effects of sympathectomy on a rat model of peripheral neuropathy. Pain 55:85-92. CrossRef Medline

Kin NW, Sanders VM (2006) It takes nerve to tell T and B cells what to do. J Leukoc Biol 79:1093-1104. CrossRef Medline

Kobayashi H, Gleich GJ, Butterfield JH, Kita H (2002) Human eosinophils produce neurotrophins and secrete nerve growth factor on immunologic stimuli. Blood 99:2214-2220. CrossRef Medline

Koopman FA, Stoof SP, Straub RH, Van Maanen MA, Vervoordeldonk MJ, Tak PP (2011) Restoring the balance of the autonomic nervous system as an innovative approach to the treatment of rheumatoid arthritis. Mol Med 17:937-948. CrossRef Medline

Lee BH, Yoon YW, Chung K, Chung JM (1998) Comparison of sympathetic sprouting in sensory ganglia in three animal models of neuropathic pain. Exp Brain Res 120:432-438. CrossRef Medline

Liu XJ, Zhang Y, Liu T, Xu ZZ, Park CK, Berta T, Jiang D, Ji RR (2014) Nociceptive neurons regulate innate and adaptive immunity and neuropathic pain through MyD88 adapter. Cell Res 24:1374-1377. CrossRef Medline

Mantyh PW (2014) The neurobiology of skeletal pain. Eur J Neurosci 39: 508-519. CrossRef Medline

McLachlan EM, Hu P (2014) Inflammation in dorsal root ganglia after peripheral nerve injury: effects of the sympathetic innervation. Auton Neurosci 182:108-117. CrossRef Medline

McLachlan EM, Jänig W, Devor M, Michaelis M (1993) Peripheral nerve injury triggers noradrenergic sprouting within dorsal root ganglia. Nature 363:543-546. CrossRef Medline

Miller RJ, Jung H, Bhangoo SK, White FA (2009) Cytokine and chemokine regulation of sensory neuron function. Handb Exp Pharmacol 194:417449. CrossRef Medline

Moalem G, Xu K, Yu L (2004) T lymphocytes play a role in neuropathic pain following peripheral nerve injury in rats. Neuroscience 129:767-777. CrossRef Medline

Mogil JS (2012) Sex differences in pain and pain inhibition: multiple explanations of a controversial phenomenon. Nat Rev Neurosci 13:859-866. CrossRef Medline

Mousa SA, Shaqura M, Brendl U, Al-Khrasani M, Fürst S, Schäfer M (2010) Involvement of the peripheral sensory and sympathetic nervous system in the vascular endothelial expression of ICAM-1 and the recruitment of opioid-containing immune cells to inhibit inflammatory pain. Brain Behav Immun 24:1310-1323. CrossRef Medline

Murata Y, Olmarker K, Takahashi I, Takahashi K, Rydevik B (2006a) Effects of lumbar sympathectomy on pain behavioral changes caused by nucleus pulposus-induced spinal nerve damage in rats. Eur Spine J 15:634-640. CrossRef Medline

Murata Y, Onda A, Rydevik B, Takahashi I, Takahashi K, Olmarker K (2006b) Changes in pain behavior and histologic changes caused by application of tumor necrosis factor-alpha to the dorsal root ganglion in rats. Spine 31:530-535. CrossRef Medline

Nance DM, Burns J (1989) Innervation of the spleen in the rat: evidence for absence of afferent innervation. Brain Behav Immun 3:281-290. CrossRef Medline

Ogon I, Takebayashi T, Iwase T, Emori M, Tanimoto K, Miyakawa T, Tera- shima Y, Kobayashi T, Tohse N, Yamashita T (2015) Sympathectomy and sympathetic blockade reduce pain behavior via alpha-2 adrenoceptor of the dorsal root ganglion neurons in a lumbar radiculopathy model. Spine 40:E1269-E1275. CrossRef Medline

Onda A, Yabuki S, Iwabuchi M, Anzai H, Olmarker K, Kikuchi S (2004) Lumbar sympathectomy increases blood flow in a dog model of chronic cauda equina compression. J Spinal Disord Tech 17:522-525. CrossRef Medline

Otoshi K, Kikuchi S, Konno S, Sekiguchi M (2010) The reactions of glial cells and endoneurial macrophages in the dorsal root ganglion and their contribution to pain-related behavior after application of nucleus pulposus onto the nerve root in rats. Spine 35:264-271. CrossRef Medline

Padro CJ, Sanders VM (2014) Neuroendocrine regulation of inflammation. Semin Immunol 26:357-368. CrossRef Medline

Perez SD, Silva D, Millar AB, Molinaro CA, Carter J, Bassett K, Lorton D, Garcia P, Tan L, Gross J, Lubahn C, Thyagarajan S, Bellinger DL (2009) Sympathetic innervation of the spleen in male Brown Norway rats: a longitudinal aging study. Brain Res 1302:106-117. CrossRef Medline

Pertin M, Allchorne AJ, Beggah AT, Woolf CJ, Decosterd I (2007) Delayed sympathetic dependence in the spared nerve injury (SNI) model of neuropathic pain. Mol Pain 3:21. CrossRef Medline

Pongratz G, Straub RH (2013) Role of peripheral nerve fibres in acute and chronic inflammation in arthritis. Nat Rev Rheumatol 9:117-126. CrossRef Medline

Ramer MS, Bisby MA (1997) Rapid sprouting of sympathetic axons in dorsal root ganglia of rats with a chronic constriction injury. Pain 70:237244. CrossRef Medline

Reynolds AD, Stone DK, Hutter JA, Benner EJ, Mosley RL, Gendelman HE (2010) Regulatory T cells attenuate Th 17 cell-mediated nigrostriatal dopaminergic neurodegeneration in a model of Parkinson's disease. J Immunol 184:2261-2271. CrossRef Medline

Rickard AJ, Young MJ (2009) Corticosteroid receptors, macrophages and cardiovascular disease. J Mol Endocrinol 42:449-459. CrossRef Medline

Ringkamp M, Eschenfelder S, Grethel EJ, Häbler HJ, Meyer RA, Jänig W, Raja SN (1999) Lumbar sympathectomy failed to reverse mechanical allodynia- and hyperalgesia-like behavior in rats with L5 spinal nerve injury. Pain 79:143-153. CrossRef Medline

Sasaki N, Kikuchi S, Konno S, Sekiguchi M, Watanabe K (2007) Anti-TNFalpha antibody reduces pain-behavioral changes induced by epidural application of nucleus pulposus in a rat model depending on the timing of administration. Spine 32:413-416. CrossRef Medline

Scadding JW (1999) Complex regional pain syndrome. In: Textbook of pain (Wall PD, Melzack R, eds), pp 835-849. New York: Churchill Livingstone.

Schaible HG, Straub RH (2014) Function of the sympathetic supply in acute and chronic experimental joint inflammation. Auton Neurosci 182:5564. CrossRef Medline

Schlereth T, Drummond PD, Birklein F (2014) Inflammation in CRPS: role of the sympathetic supply. Auton Neurosci 182:102-107. CrossRef Medline

Scola MP, Thompson SD, Brunner HI, Tsoras MK, Witte D, Van Dijk MA, Grom AA, Passo MH, Glass DN (2002) Interferon-gamma:interleukin 4 ratios and associated Type 1 cytokine expression in juvenile rheumatoid arthritis synovial tissue. J Rheumatol 29:369-378. Medline

Sekhadia MP, Nader A, Benzon HT (2011) Peripheral sympathetic blocks. In: Essentials of pain medicine (Benzon SN, et al., eds), pp 621-628. Philadelphia: Saunders.

Sekiguchi M, Kobayashi H, Sekiguchi Y, Konno S, Kikuchi S (2008) Sympathectomy reduces mechanical allodynia, tumor necrosis factor-alpha expression, and dorsal root ganglion apoptosis following nerve root crush injury. Spine 33:1163-1169. CrossRef Medline

Shimizu I, Yoshida Y, Katsuno T, Tateno K, Okada S, Moriya J, Yokoyama M, Nojima A, Ito T, Zechner R, Komuro I, Kobayashi Y, Minamino T (2012) p53-induced adipose tissue inflammation is critically involved in the development of insulin resistance in heart failure. Cell Metab 15:51-64. CrossRef Medline

Song XJ, Hu SJ, Greenquist KW, Zhang JM, LaMotte RH (1999) Mechanical and thermal hyperalgesia and ectopic neuronal discharge after chronic compression of dorsal root ganglia. J Neurophysiol 82:3347-3358. Medline

Stebbing MJ, Eschenfelder S, Häbler HJ, Acosta MC, Jänig W, McLachlan EM 
(1999) Changes in the action potential in sensory neurones after peripheral axotomy in vivo. Neuroreport 10:201-206. CrossRef Medline

Straub RH, Wiest R, Strauch UG, Härle P, Schölmerich J (2006) The role of the sympathetic nervous system in intestinal inflammation. Gut 55:16401649. CrossRef Medline

Straube S, Derry S, Moore RA, McQuay HJ (2010) Cervico-thoracic or lumbar sympathectomy for neuropathic pain and complex regional pain syndrome. Cochrane Database Syst Rev 7:CD002918. CrossRef Medline

Straube S, Derry S, Moore RA, Cole P (2013) Cervico-thoracic or lumbar sympathectomy for neuropathic pain and complex regional pain syndrome. Cochrane Database Syst Rev 9:CD002918. CrossRef Medline

Strausbaugh HJ, Green PG, Dallman MF, Levine JD (2003) Repeated, nonhabituating stress suppresses inflammatory plasma extravasation by a novel, sympathoadrenal dependent mechanism. Eur J Neurosci 17:805812. CrossRef Medline

Tanabe S, Yamashita T (2014) Repulsive guidance molecule-a is involved in Th17-cell-induced neurodegeneration in autoimmune encephalomyelitis. Cell Rep 9:1459-1470. CrossRef Medline

Walsh JT, Hendrix S, Boato F, Smirnov I, Zheng J, Lukens JR, Gadani S, Hechler D, Gölz G, Rosenberger K, Kammertöns T, Vogt J, Vogelaar C, Siffrin V, Radjavi A, Fernandez-Castaneda A, Gaultier A, Gold R, Kanneganti TD, Nitsch R, et al. (2015) MHCII-independent CD4 ${ }^{+} \mathrm{T}$ cells protect injured CNS neurons via IL-4. J Clin Invest 125:2547. CrossRef Medline

Wang H, Sun H, Della Penna K, Benz RJ, Xu J, Gerhold DL, Holder DJ, Koblan KS (2002) Chronic neuropathic pain is accompanied by global changes in gene expression and shares pathobiology with neurodegenerative diseases. Neuroscience 114:529-546. CrossRef Medline

Watanabe K, Yabuki S, Sekiguchi M, Kikuchi S, Konno S (2011) Etanercept attenuates pain-related behavior following compression of the dorsal root ganglion in the rat. Eur Spine J 20:1877-1884. CrossRef Medline

Wolf SA, Fisher J, Bechmann I, Steiner B, Kwidzinski E, Nitsch R (2002) Neuroprotection by T-cells depends on their subtype and activation state. J Neuroimmunol 133:72-80. CrossRef Medline

Woolf CJ, Ma QP, Allchorne A, Poole S (1996) Peripheral cell types contributing to the hyperalgesic action of nerve growth factor in inflammation. J Neurosci 16:2716-2723. Medline

Xie J, Park SK, Chung K, Chung JM (2001) The effect of lumbar sympathectomy in the spinal nerve ligation model of neuropathic pain. J Pain 2:270278. CrossRef Medline

Xie W, Strong JA, Meij JT, Zhang JM, Yu L (2005) Neuropathic pain: early spontaneous afferent activity is the trigger. Pain 116:243-256. CrossRef Medline

Xie W, Strong JA, Zhang JM (2010) Increased excitability and spontaneous activity of rat sensory neurons following in vitro stimulation of sympathetic fiber sprouts in the isolated dorsal root ganglion. Pain 151:447-459. CrossRef Medline

Xie W, Strong JA, Kays J, Nicol GD, Zhang JM (2012a) Knockdown of the sphingosine-1-phosphate receptor S1PR1 reduces pain behaviors induced by local inflammation of the rat sensory ganglion. Neurosci Lett 515:61-65. CrossRef Medline

Xie W, Strong JA, Kim D, Shahrestani S, Zhang JM (2012b) Bursting activity in myelinated sensory neurons plays a key role in pain behavior induced by localized inflammation of the rat sensory ganglion. Neuroscience 206 : 212-223. CrossRef Medline

Xie W, Strong JA, Ye L, Mao JX, Zhang JM (2013) Knockdown of sodium channel $\mathrm{Na}_{\mathrm{V}} 1.6$ blocks mechanical pain and abnormal bursting activity of afferent neurons in inflamed sensory ganglia. Pain 154:1170-1180. CrossRef Medline

Xie W, Strong JA, Zhang JM (2015) Local knockdown of the NaV1.6 sodium channel reduces pain behaviors, sensory neuron excitability, and sympathetic sprouting in rat models of neuropathic pain. Neuroscience 291:317-330. CrossRef Medline

Xie W, Tan ZY, Barbosa C, Strong JA, Cummins TR, Zhang JM (2016) Upregulation of the sodium channel $\mathrm{NaV} \beta 4$ subunit and its contributions to mechanical hypersensitivity and neuronal hyperexcitability in a rat model of radicular pain induced by local DRG inflammation. Pain 157:879-891. CrossRef Medline

Xie WR, Deng H, Li H, Bowen TL, Strong JA, Zhang JM (2006) Robust increase of cutaneous sensitivity, cytokine production and sympathetic sprouting in rats with localized inflammatory irritation of the spinal ganglia. Neuroscience 142:809-822. CrossRef Medline

Yanagiya Y, Yoshimura R, Hori M, Kuwahara M, Tsubone H, Sugano S (1999) The influence of chronic sympathectomy on cutaneous blood flow in the rat tail. J Vet Med Sci 61:795-801. CrossRef Medline

Zernikow B, Wager J, Brehmer H, Hirschfeld G, Maier C (2015) Invasive treatments for complex regional pain syndrome in children and adolescents: a scoping review. Anesthesiology 122:699-707. CrossRef Medline

Zhang JM, Song XJ, LaMotte RH (1999) Enhanced excitability of sensory neurons in rats with cutaneous hyperalgesia produced by chronic compression of the dorsal root ganglion. J Neurophysiol 82:3359-3366. Medline 